\title{
Corruption, Firm Governance, and the Cost of Capital*
}

\author{
Mark J. Garmaise \\ Anderson School, UCLA \\ and \\ Jun Liu \\ Anderson School, UCLA
}

${ }^{*}$ We have benefitted from discussions with Geert Bekaert, Bhagwan Chowdhry, Matthias Kahl, and Jing Liu. Yi Zhou provided able research assistance.

Correspondence to: Mark Garmaise, Anderson School at UCLA, 110 Westwood Plaza, Los Angeles, CA 90095. E-mail: mark.garmaise@anderson.ucla.edu. 


\title{
Corruption, Governance, and the Cost of Capital
}

\begin{abstract}
We develop a model of a firm owned by shareholders and administered by managers who may be either honest or dishonest. When managers have an informational advantage but shareholders retain control, dishonest managers can make false reports that distort investment and thereby reduce firm cash flows. When dishonest managers have privileged access to both information and control, firm value is further reduced and profits are diminished especially in the worst states of the world. Ineffective corporate governance combined with corruption (dishonesty) thus increases firms' exposure to systematic risk. In a cross-country empirical test of the model, we find that corruption substantially increases firm betas, particularly in countries with weak shareholder rights. Moving from the level of corruption in Canada to that in South Korea raises industry-adjusted betas by 0.35 .
\end{abstract}




\section{Introduction}

Shareholders who delegate the management of their firms forfeit access to both information and control. Shareholders' lack of knowledge and loss of power have different implications for the firm. We develop a theory of a firm owned by shareholders and administered by managers who may be either honest or dishonest. We first consider an information model in which shareholders retain control over the investment policy of the firm but receive information about project quality only through the reports of managers. Managers, who receive private benefits increasing in project size, can falsify these reports and thereby distort the firm's investment. We then consider a control model in which the managers themselves can select the firm's investment level, subject only to the constraint that the investment they select be consistent with their report. Transferring control as well as access to information to dishonest managers reduces the firm's value even further by diminishing profits especially in the worst states of the world. Weak corporate governance therefore destroys firm value in part through higher exposure to systematic risk. In a cross-country empirical test of the model, we find that corruption (our proxy for managerial dishonesty) substantially increases firm betas, suggesting that the value destruction arising from corruption-generated higher discount rates can be large. Corruption raises firm betas most strongly in countries with weak rights governing shareholder control of boards, which is consistent with our theoretical results that it is primarily transfer of control and not information that raises beta. Moving from the level of corruption in Switzerland to that in Turkey (two countries with relatively few shareholder rights) raises industry-adjusted betas by 0.25 . Across countries with substantial shareholder rights (in which investors retain control of the firm) the effects of corruption on beta are minimal.

The increase in beta generated by managerial control and dishonesty that we theoretically predict and empirically verify has several practical implications. First, international firms that invest in countries with high levels of corruption should use higher internal hurdle rates if the investment project involves ceding information and control to local managers. Second, investors setting their international asset allocations should adjust their industry-based estimates of firm betas with a corruption factor that reflects the increased systematic risk of investing in corrupt settings. Third, the stock markets in corrupt countries can be expected to exhibit greater sensitivity to the movement of world markets than would be suggested by their industry weights alone. This additional volatility may have negative spillover effects on the real economy. 
Our results provide a different perspective on some of the findings of the law and finance literature (La Porta, Lopez-de-Silanes, Shleifer and Vishny (hereafter LLSV) 1997, 1998, 1999, 2000, Beck, Demirguc-Kunt and Levine, 2003). In common with that research we find that legal institutions are important for financial outcomes (namely, firm betas), though it is the current state of antidirector rights rather than the legal origin of the commercial code that appears to be most important.

Our theory and empirical work, however, emphasize that institutions only matter in environments with relatively high levels of corruption. In countries with little corruption, antidirector rights have little effect on firm betas and discount rates. In this sense, a culture of honesty with well-formed social capital (Guiso, Sapienza, and Zingales, 2003) can act as a powerful substitute for regulatory protection of investors. The issue of how such a culture arises is beyond the scope of the paper, but the existing literature suggests that Protestant traditions, openness to foreign trade, long exposure to democracy and a British colonial history help reduce corruption (Ades and Di Tella 1999, Treisman 2000, Wei 2000, Clarke and Xu 2002).

Our model describes a firm owned by shareholders (the principals) who have neither the time nor skill to directly administer the company. Shareholders hire a manager (the agent) to run the firm. Initially the firm owns an investment opportunity, and private (idiosyncratic) information revealed later will guide the firm in choosing an optimal investment level. The firm's payoff also depends on the outcome of a public (systematic) risk factor. Managers have a preference for large projects and empire-building. They therefore have an incentive to misreport the private signal they alone receive, neglecting to inform the shareholders of bad news. In the information model, shareholders retain control of the firm, and they design an optimal investment policy that reflects the potential for false reporting on the part of management. We show that managerial deception leads to investment distortions, but they are not correlated with market outcomes. In the control model, managers set the investment level, basing it on the report they make to shareholders. Dishonest managers hide bad outcomes and therefore set the investment level consistently too high. Since shareholders do not have control, they cannot adjust the firm's investment downward to reflect the possibility of signal falsification.

The information and control models have different implications for firm value, investment, and risk. In the information model, we show that firm value is highest when the manager is certain to be honest, but that value is not necessarily monotone in the probability of managerial deception. 
Very high levels of dishonesty may be associated with relatively high firm values since the gains from deception decrease with the fraction of managers who deceive. As the proportion of dishonest managers increases, each manager deceives with less frequency and the net effect is ambiguous. In the control model, firm value is monotone in the fraction of dishonest managers, because dishonest managers with control choose the same suboptimal investment policy irrespective of how many dishonest managers there are.

In both the information and control models we show that the sensitivity of investment to project quality is (almost everywhere) increasing in the fraction of honest managers. This improved investment-quality sensitivity is especially pronounced for low quality projects. These results are related to the empirical evidence of Wurgler (2000) who shows that the efficiency of investment (essentially the sensitivity of investment to growth opportunities) is greater in countries with more developed financial sectors and stronger minority rights. Since these countries have less corruption and presumably less dishonesty, these findings provide indirect support for our predictions. Wurgler also shows that strong minority investor rights are particularly associated with less overinvestment in declining industries, which accords with our result that increased honesty most promotes improved investment efficiency for low quality projects.

The risk effects differ in the information and control models. Since the value destruction in the information model is independent of the outcome of the systematic variable, the firm beta is independent of the fraction of dishonest managers. In the control model, however, the overinvestment selected by dishonest managers essentially gives the shareholders a more levered claim on the market; ex ante overinvestment is ex post beneficial when the market outcome is good and ex post destructive when the market outcome is poor. Since the extent of overinvestment increases with the proportion of dishonest managers, we show that the firm's beta is increasing in this proportion.

We provide empirical tests of the results on risk that emerge from our theoretical model. We consider a sample of international firms and proxy for the probability of dishonesty with cross-country corruption surveys from Transparency International and the Global Competitiveness Report; each firm is assigned the corruption rating of its country. We calculate the betas of U.S. dollar firm returns with respect to a world index over the period 1997-2001. We find that corruption increases firm betas substantially, controlling for industry, leverage and per capita GDP. For example, increasing the degree of a country's corruption from the level of Canada to that of South Korea would increase the industry-adjusted beta of firms by 0.35 . To test whether the betas are increasing due 
to corruption alone or due to the combination of corruption and weak corporate governance, we examine the effect of shareholder antidirector rights described in LLSV (1998). In countries with strong antidirector rights, management is under much tighter control, although managerial deception continues to be present. Our model suggests that dishonesty has a stronger effect on firm betas in countries with weak antidirector rights, and this is what we find empirically. In countries with very strong antidirector rights corruption has no effect on beta, but when rights are moderate or weak corruption substantially increases beta. In contrast, increasing antidirector rights reduces beta only when the level of dishonesty is quite high. Adding one additional right (out of six), for example, would reduce the predicted beta of French firms by 0.015 , that of Italian firms by 0.098 and that of Mexican firms by 0.173 .

Our paper is closest in conception to Shleifer and Wolfenzon (2002), who develop an equilibrium model of entrepreneurial diversion in the context of weak investor protection. Their model makes predictions about firm value, ownership concentration, and stock market development. The entrepreneurs in the Shleifer and Wolfenzon paper are risk-neutral, so our results linking corruption and systematic risk address a question they do not consider. Our findings contrasting the effects of information asymmetries and weak corporate governance are not the focus of their work.

While we consider managerial dishonesty within firms, some of the destructive effects of corruption by public officials analyzed by Shleifer and Vishny $(1993,1994)$ and described by Mauro (1995), Wei (1997), and Kaufmann and Wei (1999) find echoes in our model. We show that corruption reduces firm values and distorts investment so it will lead to less economic growth as in Mauro (1995). More broadly, the reduction in economic efficiency described in the public corruption literature is replicated in our model of corruption within firms. In survey results Kaufmann and Wei (1999) show that firms that report paying more bribes also rate their cost of capital as being too high. This is consistent with our result that firms in countries with high corruption will have low prices and high betas.

The rest of the paper is organized as follows. Section 1 describes the model, and the results are presented in Section 2. A simple numerical example is given in Section 3, and Section 4 details our empirical tests of the main theoretical results. Section 5 concludes. 


\section{Model}

We model a firm that is considering making an investment. The organization of the firm consists of a principal and an agent. In our favored interpretation, the principal represents the body of shareholders, and the agent represents the management team. Our analysis will focus on the effects on firm value and risk of different policies for the allocation of information and control within the organization. We consider first a model in which the principal retains both access to information and control. In our second framework, we analyze the effects of granting the agent privileged access to information, while the principal exercises control. In the third model, the principal cedes both access to information and control to the agent.

The model has three periods. In the first period, the firm is sold to the principal for its market value. In the second period, signals are revealed to the agent and the principal and an investment level is chosen. In the third period, payoffs are realized.

In period two the agent receives a private quality signal $\tilde{s}$ that is informative about the quality $\tilde{q}$ of the firm's particular project. We presume that it is not possible to contract over $\tilde{s}$ (or $\tilde{q}$ ), perhaps because it is difficult to precisely specify the relevant information variables ex ante (Grossman and Hart (1986)). The agent makes a report $\hat{s}$ describing his private quality signal. In period three a public outcome $\tilde{r}$ that describes the over-all state of the economy and the average profitability of investment is revealed to all parties. The distribution of $\tilde{q}$ is independent of $\tilde{r}$, so $\tilde{q}$ may be thought of as idiosyncratic risk. Variation in $\tilde{r}$ is the source of systematic risk in the economy. (Hence the pricing kernel depends on $\tilde{r}$ and not on $\tilde{q}$.) The investment decision can be made conditional on the agent's report $\hat{s}$ of $\tilde{s}$, but must be made before the outcome of $\tilde{r}$.

We presume that the public signal $r$ is always revealed. There are two types of private signals, general and specific. With probability $e \in(0,1)$, the agent receives a general private signal that we denote by $\tilde{s}=s_{\emptyset}$. Otherwise, the agent receives a specific signal that perfectly reveals the project quality: $\tilde{s}=\tilde{q}$.

When the principal grants the agent access to information (i.e. in the second and third models), only an imperfect view of the signal is provided to the principal. If the agent has received a specific $\tilde{s}$ signal, then he may make a verifiable report $\hat{s}$ of that signal. With some probability the agent will have the ability to report that $\hat{s}=s_{\emptyset}$, even when a specific signal has been received. The variable $\tilde{m} \in\{0,1\}$ describes whether the agent has the power to hide a specific signal: when $\tilde{m}=0$ a 
specific $\tilde{s}$ is observable to the principal, and when $\tilde{m}=1$ the agent may choose not to disclose his information. With probability $a \in(0,1) \tilde{m}=1$. The signal $\tilde{m}$ is observed by both the agent and the principal. (That is, the principal is aware when the possibility of deception exists.) If the agent receives a $s_{\emptyset}$ message, however, he must report it. That is, the agent may claim not to have received specific information, but it is not possible for him to pretend to have received a specific report that he did not. The general signal may convey, on average, either better or worse news about project quality than the specific signals.

In the second and third models, in which the agent has special access to information, the agent reports the private quality $\tilde{s}$ signal he receives. In essence, the principal delegates information gathering to the agent, and this can give rise to an asymmetric information problem.

We will presume that the firm's investment is financed by a risk-free loan (we present the parameter restrictions necessary for this assumption below). The principal's net conditional expected profit is then given by

$$
\pi(I, s)=E\left[\frac{(\delta \tilde{r} \tilde{q})^{1-\alpha} I^{\alpha}}{\alpha}-I \mid s\right],
$$

where $\alpha \in(0,1)$ and $E$ represents the expectation under the risk-neutral measure. ${ }^{1}$ The above profit function is standard, with $\delta \tilde{r} \tilde{q}$ representing the productivity of the firm's production. The factor $\tilde{r}$ corresponds to the component of productivity that is influenced by systematic shocks and is observed by all parties, and the factor $\tilde{q}$ corresponds to the component of productivity that is influenced by the idiosyncratic shocks and is observed only by the agent. The factor $\delta$ represents the quality of the firm's opportunities (observable by both agent and principal), and it may vary by country. Investment decisions will be made conditional on the outcomes $\hat{s}$ and $m$.

In the model we present, the scale factor $\delta$ will not play an important role. The $\delta$ factor may vary due to cross-country differences in general economic opportunities or due to legal differences such as the ease of cash flow diversion (Shleifer and Wolfenzon (2002)). Since these issues are not central to our analysis, we will set $\delta=1$. This has no effect on returns or investment-market value ratios, but it does imply that our model does not make any predictions about scale. All the model's implications for overinvestment are therefore relative to the firm's opportunities, not relative to an absolute scale of investment.

\footnotetext{
${ }^{1}$ We set the risk-free rate equal to zero, without loss of generality.
} 
The agent is presumed to enjoy private benefits from managing a larger firm. The agent's payoff is $g(I)$, where $g$ is an increasing function. ${ }^{2}$

In the first and second models, the principal retains the ability to select the firm's investment level, but in the third model, which analyzes the effects of control, we assume that the agent decides the firm's investment policy. Contractual incompleteness implies that the principal cannot pre-specify the investment level for given outcomes of $s$ and $m$. We presume, however, that the agent is limited to choosing an investment level that is consistent with firm profit maximization given his report. The agent's power arises from his ability to file a false report and then base the investment of the firm on this report. We will discuss this version of the model in Section 2.3.

We assume that agents may be either honest or dishonest. While all agents enjoy running large firms, as described above, some agents are honest and will not falsely report a general signal or choose a suboptimal investment level, even if they may do so without fear of being caught. Other agents are dishonest and will report falsely or choose an inefficient investment policy if they benefit from doing so. Differences between actors may arise from different preferences or tastes (Erard and Feinstein 1994, Ades and Di Tella 1999). We presume that an agent is honest with probability $b \in(0,1)$ and dishonest with probability $1-b$.

We denote $r_{\min }=\min (\tilde{r}), q_{\min }=\min (\tilde{q})$ and $q_{\max }=\max (\tilde{q})$. To guarantee risk-free repayment banks will lend no more than $I_{\max }=\frac{r_{\min } q}{\alpha^{\frac{1}{1-\alpha}}}$ if $q$ is verifiable and $I_{\max }=\frac{r_{\min } q_{\min }}{\alpha^{\frac{1}{1-\alpha}}}$, otherwise. For ease of notation we define $\bar{r}=E\left[\tilde{r}^{1-\alpha}\right]^{\frac{1}{1-\alpha}}$ and $\bar{q}=E\left[\tilde{q}^{1-\alpha} \mid s_{\emptyset}\right]^{\frac{1}{1-\alpha}}$.

We will presume that

$$
\left(\frac{r_{\min }}{\bar{r}}\right)\left(\frac{q_{\min }}{\bar{q}}\right) \geq \alpha^{\frac{1}{1-\alpha}}
$$

As we will show below, this parameter restriction is sufficient to guarantee that the investment selected by the firm will be financed by the banks and that the principal's limited liability constraint does not bind. ${ }^{3}$

\footnotetext{
${ }^{2}$ In a previous draft we considered an optimal mechanism design in which the principal could compensate the agent with transfers in addition to setting the investment policy. All the results in the current paper hold in that model as well, though the exposition is substantially more involved with little gain in economic intuition. The draft with the optimal mechanism is available from the authors upon request.

${ }^{3}$ Alternatively, we can presume that the principal faces unlimited liability.
} 


\section{Results}

\section{$2.1 \quad$ First-Best}

We begin by assuming that the manager (agent) is honest. In this case, the manager will not attempt to hide his signal $s$. This is equivalent to presuming that the principal retains both access to information and control. We consider the optimal investment problem faced by the principal.

If the agent reports a specific signal $\tilde{s}=q$, the optimal investment, which depends on $q$, is determined by the following first-order condition (FOC)

$$
E\left[\tilde{r}^{1-\alpha}\right] q^{1-\alpha} I_{q}^{* \alpha-1}-1=0
$$

This gives rise to

$$
I_{q}^{*}=q E\left[\tilde{r}^{1-\alpha}\right]^{\frac{1}{1-\alpha}}=q \bar{r} .
$$

The optimal investment is low when the idiosyncratic productivity $q$ is low. The realized optimal profit is

$$
(\tilde{r} q)^{1-\alpha} \frac{I_{q}^{* \alpha}}{\alpha}-I_{q}^{*}=q \bar{r}\left(\frac{\tilde{r}^{1-\alpha}}{\alpha E\left[\tilde{r}^{1-\alpha}\right]}-1\right) .
$$

The agent may also receive a general signal $s_{\emptyset}$. Let us denote the investment in this case as $I_{\emptyset}^{h}$. We find

$$
I_{\emptyset}^{h}=E\left[(\tilde{r} \tilde{q})^{1-\alpha} \mid \tilde{s}=s_{\emptyset}\right]^{\frac{1}{1-\alpha}}=\bar{r} \bar{q} .
$$

When there is a general signal, there are efficiency losses: there is under-investment if $q>\bar{q}$ and over-investment if $q<\bar{q}$. Condition (2) guarantees that the optimal investment is always financed by the banks.

The realized profit in this case is given by

$$
\bar{r} \bar{q}\left[\frac{(\tilde{r} \tilde{q})^{1-\alpha}}{\alpha E\left[(\tilde{r} \tilde{q})^{1-\alpha} \mid \tilde{s}=s_{\emptyset}\right]}-1\right] .
$$

Assuming that there is a proportion $e$ of agents who receive a general signal, the total expected profit of the principal conditional on $r$ when the agent is honest is described by

$$
\begin{aligned}
\pi_{h}(r) \equiv & e \bar{r} \bar{q}\left[\frac{r^{1-\alpha}}{\alpha E\left[\tilde{r}^{1-\alpha}\right]}-1\right]+(1-e) E[\tilde{q}] \bar{r}\left[\frac{r^{1-\alpha}}{\alpha E\left[\tilde{r}^{1-\alpha}\right]}-1\right] \\
& =\frac{\bar{r}^{\alpha}(e \bar{q}+(1-e) E[\tilde{q}])}{\alpha}\left[r^{1-\alpha}-\alpha E\left[\tilde{r}^{1-\alpha}\right]\right] .
\end{aligned}
$$


The main point emerging from this analysis is that when the investment level is chosen to reflect the expected quality (given all the information), the profit conditional on $r$ may be expressed as a multiple of $\left[r^{1-\alpha}-\alpha E\left[\tilde{r}^{1-\alpha}\right]\right]$. In the following sections we will show that in the presence of asymmetric information this functional form of the payoff is maintained, but transferring control to the agent can result in a profit with a different shape that will have changed risk characteristics.

Let $p_{h}=E\left[\pi_{h}(r)\right]$ denote the market price of the optimal profit. The beta of the firm when the agent is honest is defined by

$$
\beta^{H} \equiv \frac{\operatorname{cov}\left(\frac{\pi_{h}(r)}{p_{h}}, r\right)}{\sigma^{2}},
$$

where $\sigma^{2}$ is the variance of $r$ and $c o v$ is the covariance under the true physical measure.

As we will show, the firm's expected profit is maximized when the principal has both information and control (or, equivalently, when the agent is honest). In general, however, firms are owned by principals who are unable to manage their firms directly, due to time and skill constraints. Firms are managed instead by agents who are wealth-constrained and who are unable to purchase the firms they run. These agents do not always manage firms in the best interests of their principals.

\section{$2.2 \quad$ Asymmetric Information}

We now introduce the possibility that agents may be dishonest, and we presume that the agents who run the firm have an informational advantage relative to principals (Myers and Majluf, 1984). We will assume in this section, however, that the principal retains the ability to set the investment level, perhaps due to forceful investor protection laws. If deception is possible $(m=1)$, dishonest agents may report either the true specific signal $\hat{s}=q$ or the general signal $\hat{s}=s_{\emptyset}$; they cannot report $\hat{s} \notin\left\{q, s_{\emptyset}\right\}$. The principal's problem is to choose an optimal investment policy given the agent's report of $\hat{s}$ and the observed value of $\tilde{m}$. For any $\hat{s}=q \neq s_{\emptyset}$, the principal will choose investment $I_{q}^{*}=q \bar{r}$, as in the first best case. ${ }^{4}$ If $\hat{s}=s_{\emptyset}$ the principal's optimal investment $I_{\emptyset}^{D}(m)$ will depend on the observed value of $m$. If $m=0$, no deception is possible so the agent must have received a general signal. This is identical to the case of full honesty, so $I_{\emptyset}^{D}(0)=I_{\emptyset}^{h}$.

If $m=1$ the principal recognizes that a dishonest agent with a low specific signal may camouflage the bad news by reporting $\hat{s}=s_{\emptyset}$. The agent has a preference for greater investment and investment

\footnotetext{
${ }^{4}$ We assume in this discussion that due to contractual incompleteness the principal cannot commit to an investment level conditional on the agent's report of $q$. The main results in this section, however, hold in a model with commitment as well.
} 
is increasing in the reported signal, so if the true specific signal is very low the agent may be better off reporting a general signal. The following lemma describes the strategy of the dishonest manager and the optimal investment by the principal $I_{\emptyset}^{D}(1)$ when deception is possible.

Lemma 1 When deception is possible $(m=1)$, there is a $q(b)$ such that for $\tilde{s}=q \leq q(b)$, a dishonest agent reports $\hat{s}=s_{\emptyset}$ and receives investment $I_{\emptyset}^{D}(1)=q(b) \bar{r}$. The cutoff signal $q(b)$ is the unique value satisfying

$$
q(b)=\left(\frac{e \mathrm{E}\left[q^{1-\alpha} \mid \tilde{s}=s_{\emptyset}\right]+(1-b)(1-e) \mathrm{E}\left[q^{1-\alpha} 1_{q<q(b)}\right]}{e+(1-b)(1-e) \mathrm{E}\left[1_{q<q(b)}\right]}\right)^{\frac{1}{1-\alpha}} .
$$

The function $q(b)$ is increasing in $b$ and $q(b) \leq \bar{q}$.

The analysis above and Lemma 1 yield a description of the agent's reporting strategy and the principal's optimal investment decision.

Lemma 2 When the agent is granted privileged access to information, he makes the following reports:

a) Honest agents report $\hat{s}(s, m)=s$.

b) Dishonest agents report

$$
\hat{s}(s, m)= \begin{cases}s & \text { if } m=0 \text { or } s=s_{\emptyset} \text { or } s=q \geq q(b) \\ s_{\emptyset} & \text { otherwise. }\end{cases}
$$

The principal makes the following investment decisions:

$$
I_{d}(\hat{s}, m)= \begin{cases}I_{q}^{*} & \text { if } \hat{s}=q \\ \bar{r} \bar{q} & \text { if } \hat{s}=s_{\emptyset} \text { and } m=0 \\ \bar{r} q(b) & \text { if } \hat{s}=s_{\emptyset} \text { and } m=1\end{cases}
$$

Honest agents always report their true signals, but dishonest agents report strategically. If a dishonest agent receives a poor specific signal, he will choose to report a general signal when deception is possible. If a specific signal is reported, the principal knows that it must be a true report, and he selects the optimal investment level $I=I_{q}^{*}$. If a general signal is reported and deception is not possible, the principal again knows that it is a true report and selects the optimal investment level $I=\bar{r} \bar{q}$. If a general signal is reported and deception is possible, the principal understands that the true signal may be general or it may be a low quality specific signal. The 
principal chooses an investment level that reflects the average quality of all those who report this general signal, and this investment is given by $I=\bar{r} q(b)$. This investment depends on $b$, because as $b$ increases there are fewer dishonest agents and the principal regards a general report as more likely being a true report. This implies that the gains from deception for dishonest agents increase, since the principal is less suspicious of a general report. Consequently, in equilibrium, the quality threshold below which dishonest agents report a falsified general signal increases in $b$.

With Lemma 2 in hand we can calculate the principal's payoff, which is given in Lemma 3.

Lemma 3 When the agent is dishonest, the principal's expected profit conditional on $r$ is

$$
\pi_{d}(r, b)=K \frac{\bar{r}^{\alpha}}{\alpha}\left[r^{1-\alpha}-\alpha E\left[\tilde{r}^{1-\alpha}\right]\right]
$$

where

$$
\begin{gathered}
K=E(\tilde{q})(1-e)((1-a)+a b) \\
+\bar{q}(1-a) e+E\left[\tilde{q} 1_{\{\tilde{q} \geq q(b)\}}\right] a(1-e)(1-b) \\
+a q(b)\left(e+(1-b)(1-e) E\left[1_{\{\tilde{q} \leq q(b)\}}\right]\right)
\end{gathered}
$$

We first note that if all agents are honest, then $q(b)=\bar{q}$ and the principal's payoff in the information model is equal to the first-best outcome. For $b<1$ there are four basic cases that emerge in this set-up and they correspond to the four components of $K$. The first term in $K$ arises from the case in which the agent receives a specific signal and either deception is not possible or the agent is honest. When this occurs the specific signal is reported and the optimal investment is implemented. In the second case, deception is not possible and a general signal is reported. The principal knows that this is a true report and implements $I=\bar{r} \bar{q}$. The third term reflects dishonest agents who receive specific signals and who can engage in deception but choose not to, because their quality is so high. They report the true signal and receive investment $I_{q}^{*}$. The last term describes the principal's payoff when the agent reports a general signal and deception is possible. In this case the principal must adjust his investment to incorporate the possibility of a false report by a dishonest agent with a low specific signal. 
Deception on the part of the agent induces investment distortions. The principal is forced to grant more agents an "average" investment level rather than the optimal investment for their $q$, because dishonest agents with low $q$ outcomes will claim to have received a general signal. This distortion, however, depends on the idiosyncratic outcome $q$ which is uncorrelated with the market return $r$. Moreover, in all cases the principal's investment given any agent report reflects the expected quality signal of all agents who make that report. Consequently, as in the first-best case, the principal's payoff is always a multiple of $\left[r^{1-\alpha}-\alpha E\left[\tilde{r}^{1-\alpha}\right]\right]$. The efficiency loss due to deception is a fixed fraction of the full information payoff.

Proposition 1 describes how the principal's investment changes with variation in the project quality.

Proposition 1 In the information model, expected investment increases with project quality:

$$
\frac{\partial E\left[I_{d}(\hat{s}(s, m), m) \mid q\right]}{\partial q}= \begin{cases}\bar{r}(1-e) & \text { if } q>q(b) \\ \bar{r}(1-e)(1-a+a b) & \text { if } q<q(b)\end{cases}
$$

The sensitivity of investment to project quality is increasing in honesty b for low qualities:

$$
\frac{\partial^{2} E\left[I_{d}(\hat{s}(s, m), m) \mid q\right]}{\partial q \partial b}= \begin{cases}0 & \text { if } q>q(b) \\ \bar{r} a(1-e) & \text { if } q<q(b)\end{cases}
$$

The function $E\left[I_{d}(\hat{s}(s, m), m) \mid q\right]$ is not differentiable at $q=q(b)$.

The principal chooses a higher investment level when the reported signal is better. Although the agent can falsify the signal, nonetheless expected investment is increasing in project quality. When the agent is honest he reports specific signals more frequently, which enables the principal to more often view the quality before choosing an investment level. This results in an increased sensitivity of investment to quality. The effects of increasing honesty are particularly important for low quality projects because it is dishonest agents with precisely these projects who engage in false reporting. We will discuss the empirical implications of this proposition in our discussion of the parallel proposition in the control section, Proposition $4 .^{5}$

We let $p_{d}(b)=E\left[\pi_{d}(r, b)\right]$ denote the market price of the principal's optimal profit.

\footnotetext{
${ }^{5}$ We note that the conditional expected profit and investment described in Lemma 3 and Proposition 1, respectively, are identical under the risk-neutral and true physical probability measures, since the expected profit is conditioned on $\tilde{r}$ and the investment is independent of $\tilde{r}$.
} 
Proposition 2 The market value of the principal's payoff when the agent is honest is always higher than the value of his payoff when the agent is dishonest:

$$
p_{d}(b) \leq p_{h}
$$

for all $b \in[0,1]$.

When the agent is always honest, the principal receives specific reports whenever possible and assigns an optimal average investment level when he receives general reports. As a result, the principal obtains a higher expected payoff in the fully honest first-best case than he receives when the agent is sometimes dishonest and may make false reports. While Proposition 2 shows that the full information payoff is greater than the asymmetric information payoff, it is not possible to show in general that the principal's payoff is increasing in $b$. Some intuition for this may be derived from considering the effects of changing $b$ on the composition of agents who report general signals. As $b$ increases, there are fewer dishonest agents, but more of them hide their signals (i.e. $q(b)$ is increasing in $b$, as we showed in Lemma 1 ). It is clear that there is no deception when $b=1$, but the effect on the principal's payoff need not be monotone in $b$. As $b \downarrow 0$, the ratio of dishonest agents to agents who truly receive general signals can be so high that the payoff to deception is quite low. For example, suppose that this ratio rises to infinity. (This does not occur in our model since dishonest agents can also receive general signals, but the argument will serve to illustrate our point.) In this case it cannot be an equilibrium for any agent to issue a false report, since all such agents would receive an investment reflecting their average type, and agents with types above this average would prefer to instead truly report their type. That is, in this case, the agents would face a perfect lemons problem and no agent would report falsely. This shows that deception can be reduced (and the principal's payoff increased) as $b$ falls. The trade-off between the number of dishonest agents and the frequency with which they cheat is not monotone in $b$, so we can say no more than that the optimum is achieved at full honesty, $b=1$.

The beta of the profit is defined to be

$$
\beta^{D}(b) \equiv \frac{\operatorname{cov}\left(\frac{\pi_{d}(r)}{p_{d}}, r\right)}{\sigma^{2}} .
$$

Proposition 3 The firm beta is independent of the proportion $b$ of dishonest agents:

$$
\frac{\partial \beta^{D}(b)}{\partial b}=0
$$


In fact, we have

$$
\beta^{D}=\beta^{H}
$$

When there is an information asymmetry and deception about the idiosyncratic productivity shock the principal experiences an efficiency loss. Since the loss in profit is proportional to $\left[r^{1-\alpha}-\alpha E\left[\tilde{r}^{1-\alpha}\right]\right]$, however, the beta of the first-best profit and the profit with deception are the same. Thus, for example, under the CAPM investors will require the same expected return from a firm with asymmetric information as from a firm with perfect information. As Proposition 2 makes clear, on the other hand, the price of a firm that is subject to asymmetric information and managerial deception will be lower than the price of an otherwise identical firm with perfect information, because the expected profit of the former is lower than the expected profit of the latter.

These results are consistent with the findings of the empirical accounting disclosure literature which has demonstrated that there are price effects from information. Proposition 2 shows that for a given level of book assets (or current earnings), a firm facing information problems will have a lower price because its growth opportunities will be less valuable. Botosan (1997) argues that disclosure reduces the cost of capital for firms with low analyst following. Bhattacharya, Daouk, Welker (2002) show that earnings opacity increases the cost of equity. Since these papers relate expected accounting variables to the current price in order to derive the cost of capital, the lower prices in the presence of asymmetric information predicted by Proposition 2 would yield the higher costs of equity these authors find. In related work, Easley, Hvidkjaer and O'Hara (2002) find that firms with higher probability of information-based trading have higher book-to-market ratios, which is also consistent with Proposition 2. All these studies control for beta, so they are essentially consistent with Propositions 2 and 3: firms subject to information asymmetries trade at a discount, even accounting for systematic risk. In the following section we will discuss how transfer of control to the agent can generate changes in firm betas.

\subsection{Control}

In this section, we consider a model in which the principal transfers both information and control to the agent. It may be, for example, that the legal environment in which the firm operates makes board-management collusion very easy. In this case, the agent (manager) will always in effect be 
able to wrest control from the principal (shareholders). Alternatively, monitoring the agent may be so difficult in some settings (or require skills and attention that the principal lacks) that the principal must transfer real authority (Aghion and Tirole, 1997).

When the agent is granted control, we assume that he still faces some constraints on his power. We presume that the agent is required as before to make a verifiable report $\hat{s}$ on the realization of the quality signal. The agent's investment decision must maximize the value of the firm given the report he has made. The evaluation signal $m$, however, is not verifiable. The agent's power, therefore, derives from his ability to make a false report and then implement an investment level that is consistent with that report. Any choice of $I$ satisfying

$$
I \in \operatorname{argmax}_{I} \pi(I, \hat{s})
$$

will be regarded by the courts as a reasonable business decision on the part of the manager. ${ }^{6}$ The following lemma describes the investment decisions $I(s, m)$ made by the agent conditional on the outcomes of the signals.

Lemma 4 When the agent is granted control, he makes the following investment decisions:

a) Honest agents set

$$
I_{c}(s, m)= \begin{cases}I_{q}^{*} & \text { if } s=q \\ \bar{r} \bar{q} & \text { if } s=s_{\emptyset}\end{cases}
$$

b) Dishonest agents set

$$
I_{c}(s, m)= \begin{cases}I_{q}^{*} & \text { if }\left(m=0 \text { and } s=q \neq s_{\emptyset}\right) \text { or } s=q \geq \bar{q} \\ \bar{r} \bar{q} & \text { otherwise. }\end{cases}
$$

Honest agents are presumed to report truthfully, so they choose investment levels as in the first-best case. When deception is not possible, dishonest agents report truthfully and choose the first-best investment level. When deception is possible, dishonest agents who receive specific signals can either report truthfully or report $\hat{s}=s_{\emptyset}$. The optimal investment given that $s=s_{\emptyset}$ is $I=\bar{r} \bar{q}$, while the investment that must be selected when $\hat{s}=q \neq s_{\emptyset}$ is $I=\bar{r} q$. Consequently, dishonest agents who receive a specific signal that they can falsify report truthfully if and only if their signal

\footnotetext{
${ }^{6}$ Assuming instead that the agent can simply choose any investment up to a certain fixed level yields similar results.
} 
exceeds $\bar{q}$. When their signal is lower, they prefer to report a general signal. Lemma 5 describes the principal's payoff when the agent has control.

Lemma 5 When the agent is granted control, the principal's expected profit conditional on $r$ is

$$
\pi_{c}(r, b)=\frac{\bar{r}^{\alpha}}{\alpha}\left[K_{1}\left[r^{1-\alpha}-\alpha E\left[\tilde{r}^{1-\alpha}\right]\right]+K_{2}\left(r^{1-\alpha}-\alpha E\left[\tilde{r}^{1-\alpha}\right] \frac{\bar{q}^{1-\alpha} E\left[1_{\{\tilde{q} \leq \bar{q}\}}\right]}{E\left[\tilde{q}^{1-\alpha} 1_{\{\tilde{q} \leq \bar{q}\}}\right]}\right)\right],
$$

where

$$
\begin{aligned}
& K_{1}=E(\tilde{q})(1-e)((1-a)+a b) \\
& +\bar{q} e+E\left[\tilde{q} 1_{\{\tilde{q} \geq \bar{q}\}}\right] a(1-e)(1-b)
\end{aligned}
$$

and

$$
\left.K_{2}=a(1-e)(1-b) \bar{q}^{\alpha} E\left[\tilde{q}^{1-\alpha} 1_{\{\tilde{q} \leq \bar{q}\}}\right]\right)
$$

The profit $\pi_{c}$ may be contrasted with the profit $\pi_{d}$ in the asymmetric information case that is described in Lemma 3. In both cases, the optimal investment is implemented when the signal is specific and either the agent is honest or deception is not possible. The first-best profit is achieved when all managers are honest. Whenever the signal is general, an agent with control sets the investment at $I=\bar{r} \bar{q}$ which yields the second term in $K_{1}$ above. In the information model, by contrast, if deception is possible, the principal will be suspicious of general reports and only grant $I=\bar{r} q(b)$ to agents who report general signals. (Lemma 1 shows that $q(b) \leq \bar{q}$.) The threshold for reporting truthfully by dishonest agents who receive specific signals and can deceive is $\bar{q}$ in the control model and $q(b)$ in the information model. This difference arises because of the different investments received by agents reporting general signals in the two models.

The agent's strategy in the control model has implications for the firm's investment, profit and risk.

Proposition 4 In the control model, expected investment increases with project quality:

$$
\frac{\partial E\left[I_{c}(s, m) \mid q\right]}{\partial q}= \begin{cases}\bar{r}(1-e) & \text { if } q>\bar{q} \\ \bar{r}(1-e)(1-a+a b) & \text { if } q<\bar{q}\end{cases}
$$


The sensitivity of investment to project quality is increasing in honesty b for low qualities:

$$
\frac{\partial^{2} E\left[I_{c}(s, m) \mid q\right]}{\partial q \partial b}= \begin{cases}0 & \text { if } q>\bar{q} \\ \bar{r} a(1-e) & \text { if } q<\bar{q}\end{cases}
$$

The function $E\left[I_{c}(s, m) \mid q\right]$ is not differentiable at $q=\bar{q}$.

Two points emerge from a comparison of Propositions 1 and 4. First, in both the information and control models, an increase in honesty improves the average productivity of investment when project quality is low (i.e. for $q<q(b)$ and for $q<\bar{q}$ in the two models, respectively). Second, granting the agent control in addition to privileged access to information reduces the investmentquality sensitivity for a range of low-medium project qualities (i.e. for $q \in(q(b), \bar{q})$ ).

Propositions 1 and 4 find indirect support in the empirical evidence of Wurgler (2000) who shows that the efficiency of investment (essentially the sensitivity of investment to growth opportunities) is greater in countries with more developed financial sectors. Since these countries have less corruption (Treisman, 2000) and presumably less dishonesty, Propositions 1 and 4 predict that investment in more developed countries will be more sensitive to project quality, which is essentially Wurgler's result. ${ }^{7}$

Wurgler also finds that strong minority investor rights are positively related to investment efficiency and are particularly associated with less overinvestment in declining industries. It is not straightforward to interpret Wurgler's finding in the context of our model, because he does not control for a measure of dishonesty. (Distinguishing the effects of corruption and weak governance is not the focus of his work.) On the one hand, in our empirical work we show that investor rights are negatively correlated with corruption. This suggests that overinvestment in declining industries may be less severe when managers are more honest, which accords with the result in Propositions 1 and 4 that increasing honesty most improves the productivity of investments when firm quality is low. On the other hand, if we regard minority investor rights as a device to keep control in the hands of the shareholders, then Propositions 1 and 4 suggest that these rights should increase investment-quality sensitivity, but only for a low-medium range of project qualities. From the standpoint of our theory, it is important to distinguish between managerial honesty and control. In our empirical work below we will use separate proxies for the manager's propensity to exploit the principal and for his power to do so.

\footnotetext{
${ }^{7}$ Almeida and Wolfenzon (2003) consider the interaction between investor protection, firm's external financing needs, and the efficiency of capital allocation.
} 
We let $p_{c}(b)=E\left[\pi_{c}(r, b)\right]$ denote the market price of the principal's optimal profit in the control model.

Proposition 5 The market value of the principal's payoff is increasing in b:

$$
\frac{\partial p_{c}(b)}{\partial b} \geq 0 .
$$

Furthermore, the value of the principal's payoff when the agent is granted control is always lower than the value of his payoff when the agent is granted only information:

$$
p_{c}(b) \leq p_{d}(b) .
$$

for all $b \in[0,1]$.

Increasing honesty improves the principal's payoff since the agent chooses the profit-maximizing investment level more often. Proposition 5 also shows that the principal suffers from the transfer of control to the agent. In both the information and control models the agent makes a report to the principal and the investment is based on this report. In the information model, however, the principal can adjust the investment downward to reflect the expected signal falsification, while in the control model the agent chooses the investment as if the signal were always truthful. This leads to inefficient overinvestment (relative to the firm's opportunities) in the control model, which, in turn, reduces the principal's expected payoff. This suggests that improved corporate governance can increase the value of the firm by assuring that control resides with the shareholders and not the management.

This result is consistent with the extensive literature surveyed by Shleifer and Vishny (1997) documenting the importance of corporate governance to firm value. It is the general thrust of this research that poor corporate governance (the granting of control to the agent, in our setting) destroys shareholder value. Recent contributions include Gompers, Ishii and Metrick (2003) who show that firms with stronger shareholder rights have higher profits and firm values, Core, Holthausen and Larcker (1999) who show that firms with more effective governance structure have better operating performance, and Himmelberg, Hubbard and Love (2002) who develop a model in which investor protection can ameliorate agency conflicts between risk-averse insiders and well-diversified outsiders. 
The most important feature distinguishing $\pi_{c}$ from both $\pi_{d}$ and $\pi_{h}$ is that, as shown in Lemma $5, \pi_{c}$ is not proportional to $\left[r^{1-\alpha}-\alpha E\left[\tilde{r}^{1-\alpha}\right]\right]$. The differing shape of the principal's payoff in the control model arises from the investment policy of a dishonest agent with a low specific signal who can deceive. Such an agent receives an investment $I=\bar{r} \bar{q}$ that is too high relative to his signal. In the first-best and information models, the average investment granted is optimal, relative to the agent's expected quality. In the control model, the average investment selected by the agent exceeds the level appropriate for his expected quality, given the firm's opportunities. It is the case in both the first-best and information models that the principal will sometimes over-invest and sometimes under-invest. In the control model, however, the agent systematically over-invests; his over-investment is more frequent than his under-investment. (We emphasize that these findings are relative to a given level of opportunity $\delta$ - the model does not make predictions about overall firm scale.)

Relative to the optimal investment level, when the market performs well over-investment leads to a better ex post outcome, and when the market performs poorly over-investment generates a worse payoff. As a result of the agent's systematic over-investment, the principal in effect holds a more leveraged position in the market portfolio in the control model. ${ }^{8}$

The beta of the profit is defined to be

$$
\beta^{C} \equiv \frac{\operatorname{cov}\left(\frac{\pi_{c}}{p_{c}}, r\right)}{\sigma^{2}} .
$$

Proposition 6 The beta $\beta^{C}$ decreases with the level of honesty b:

$$
\frac{\partial \beta^{C}(b)}{\partial b}<0
$$

Proposition 6 shows that when corporate governance is weak, firm betas increase with managerial dishonesty. Propositions 3 and 6 together show the effect of dishonesty in increasing beta is driven by the transfer of control to managers, not by managers' informational advantage over shareholders.

The empirical literatures on disclosure and corporate governance that we have cited in this section and the previous one establish that information and control problems can diminish firm

\footnotetext{
${ }^{8}$ Technically this can be seen from the fact that $\frac{\bar{q}^{1-\alpha} E\left[1_{\{\tilde{q} \leq \bar{q}\}}\right]}{E\left[\tilde{q}^{1-\alpha} 1_{\{\tilde{q} \leq \bar{q}\}}\right.} \geq 1$. This implies that the principal in essence holds a larger short position in the risk-free asset in the control model.
} 
values. We propose in Proposition 6 that ineffective corporate governance can have an especially deleterious effect by particularly reducing firm payoffs when the market outcome is poor. We argue, therefore, that information problems reduce expected cash flows, and that transfer of control to management reduces firm value even further in part through an increase in the firm beta and discount rate. This precise mechanism has not been documented in the empirical literature. ${ }^{9}$ In the next section we show in a numerical example that the discount rate effects we describe can theoretically have a very large impact on firm value.

In the empirical section following, we provide some empirical validation for Propositions 3 and 6; we show that firm betas increase substantially with corruption (our measure of dishonesty), and that this effect is strongest when shareholders have only weak control of boards.

\section{A Numerical Example}

We consider a numerical analysis of the value and risk effects generated by the control model. We assume an exponential distribution for $q \in[1,+\infty), f(q)=\gamma e^{\gamma(1-q)}$, with $\gamma>0$. We let $r=\mu+\sigma \epsilon$, where $\epsilon$ is a mean-zero random variable, and we will assume that the pricing kernel is given by $m=r_{f}^{-1}(1-\lambda \epsilon)$, where the market price of risk $\lambda$ is given by $\lambda=\frac{\mu-r_{f}}{\sigma}$. This pricing kernel gives rise to the CAPM pricing relation; that is, for an arbitrary payoff $\pi^{*}$, its price $p$ is given by

$$
p=\frac{\hat{E}\left[\pi^{*}\right]}{r_{f}+\beta\left(\mu-r_{f}\right)},
$$

where $\hat{E}$ is the expectation under the physical measure. To keep the above pricing kernel positive, there must be an upper bound on the return of the market:

$$
r \leq r_{\max } \equiv \mu+\frac{\sigma}{\lambda}
$$

To compute the valuation effect of the change in beta, we will assume that a firm generates the profit $\pi^{*}$ in perpetuity, therefore,

$$
V=\frac{\hat{E}\left[\pi^{*}\right]}{r_{f}+\beta\left(\mu-r_{f}\right)-1} .
$$

\footnotetext{
${ }^{9}$ Easley, Hvidkjaer and O'Hara (2002) find that their probability of information-based trading measure is positively correlated with beta. They do not, however, control for the quality of firm corporate governance. If firms on average face significant control problems then Proposition 6 suggests that betas should increase in the probability of managerial dishonesty, which accords with the Easley, Hvidkjaer and O'Hara (2002) result. If the CAPM is not the true asset pricing model, the systematic risk effects generated by poor corporate governance might also predict higher expected returns beyond those captured by beta, as Easley, Hvidkjaer and O'Hara find. Easley and O'Hara (2004) provides a theoretical treatment of the relationship between information asymmetries and systematic risk. We attempt to disentangle the information and control effects in our empirical section.
} 
Table 1: Numerical Results

\begin{tabular}{lccccc}
\hline \hline$b$ & 1 & 0.9 & 0.5 & 0.1 & 0 \\
\hline$V$ & 21.507 & 20.183 & 15.579 & 11.899 & 11.099 \\
$\hat{E}\left[\pi^{*}\right]$ & 1.467 & 1.439 & 1.327 & 1.215 & 1.187 \\
$\beta$ & 0.967 & 1.026 & 1.304 & 1.642 & 1.738 \\
pct & n.a. & 0.689 & 0.653 & 0.614 & 0.604 \\
\hline \hline
\end{tabular}

The parameters are as follows: $\tilde{q}$ has the exponential distribution over $[1,+\infty)$ with $\gamma=5, \bar{q}=3, a=0.9, e=0.1, \alpha=0.5$, and $r$ is normally distributed with mean $7 \%$ and volatility $16 \%$, with $r$ truncated at 2 standard deviations from above from below. The riskfree return is $2 \%$. The limited liability condition (2) holds for these parameters. Firm value is given by $V$, expected cash flows by $\hat{E}\left[\pi^{*}\right]$, and firm beta by $\beta$. The row pct describes the proportion of the decline in value relative to the fully honest base case that is due to the change in beta.

The percentage change in value relative to the fully honest base case due to the change in beta is given by

$$
\operatorname{pct}=\left|\frac{\frac{\left(\mu-r_{f}\right) \Delta \beta}{r_{f}+\beta\left(\mu-r_{f}\right)-1}}{\frac{\Delta \hat{E}\left[\pi^{*}\right]}{\hat{E}\left[\pi^{*}\right]}-\frac{\left(\mu-r_{f}\right) \Delta \beta}{r_{f}+\beta\left(\mu-r_{f}\right)-1}}\right| .
$$

The results are given in Table 1. Several implications emerge from the table. First, the decline in firm value due to dishonesty and transfer of control can be large. Second, weak corporate governance can lead to substantially increased firm betas. Third, in this example a large portion of the decline in firm value (over 60 percent) arises from the increase in discount rate due to the higher beta. While expected cash flows do drop substantially, firm value destruction is largely driven by the discount rate effect. In the next section, we empirically estimate the change in beta due to managerial dishonesty and transfer of control and find significant increases broadly in line with the values in Table 1.

\section{Empirical Tests}

In this section we provide empirical tests of some of the central results that emerge from our theoretical model. The first result we test is Proposition 6 which states that when managers have control firm betas should increase in the probability of dishonesty. To test this hypothesis, we consider a sample of international firms. To proxy for the probability of dishonesty we use crosscountry corruption surveys (to be discussed below) and assign each firm the corruption rating of its country of domicile. We find evidence in favor of Proposition 6; controlling for industry, firms in 
more corrupt countries tend to have higher betas. The second result we test is a joint implication of Propositions 3 and 6. Taken together these two propositions show that the effect of dishonesty in increasing firm betas is strongest when shareholders have weak control over boards. We make use of differences in shareholder rights across countries to test this prediction, and we present empirical results in support of the theory.

Our main data source is Datastream. Datastream provides firm U.S. dollar returns, equity market values, debt values and industry groupings. The initial sample with at least partial return data consists of 5950 firms. We match the Datastream industry classification to the Global Industry Classification Standard (GICS) developed by Standard and Poor's and MSCI. The GICS system divides firms into 23 industry groups.

To measure perceived corruption levels we use two sources. The first is the Transparency International (TI) Corruption Perceptions Indices from 1997-2001. Each year's index represents an average of results from approximately ten surveys on corruption provided by a variety of sources. This data has been used in several studies (a detailed description is given in Treisman, 2000). The corruption that is the focus of the TI indices is typically that of public officials, not employees of private firms. In the original TI ratings, higher score indicate less corruption. For ease of interpretation we define TI (Corruption) to be ten minus the original TI rating. This gives a measure that is increasing in corruption. TI (Corruption) scores range from 0.152 in Denmark to 7.996 in Indonesia.

Our second data corruption source is the Global Competitiveness Reports (GCR) of 1997-2000 and the combined report of 2001-2002. This source provides survey data on irregular payments in government services and loan applications. The GCR is often included in the TI index, and it is a single annual survey, rather than an average of surveys. We define GCR (Corruption) to seven minus the original GCR rating, which yields a measure increasing in corruption. GCR scores range from 0.244 in Finland to 4.498 in Indonesia.

To measure shareholders ability to control boards of directors we use LLSV (1998)'s countyby-county "Antidirector rights" measure. This index aggregates a series of shareholder rights. ${ }^{10}$ Higher scores on the index indicate that shareholders have greater power to control and potentially

\footnotetext{
${ }^{10}$ The series consists of the following six rights: (1) Shareholders can mail their proxy votes, (2) shareholders are not required to deposit their shares with the firm before a shareholder meeting, (3) cumulative voting for directors is permitted, (4) oppressed shareholder minorities have legal recourse, (5) the minimum percentage of share capital required to call for an extraordinary meeting is less than 10 percent, and (6) shareholders have preemptive rights to new issues.
} 
remove abusive directors. Scores range from zero in Belgium to five in the U.K., U.S. and several other (typically English legal origin) countries. LLSV (1998) also provide evidence on the legal origin of commercial codes and company law.

As a control, we also consider the effects of per capita GDP on firm betas. We gathered 2001 per capita GDP data from the CIA factbook.

A list of all the countries included in this study is given in Table 2. Table 3 presents summary statistics and a correlation table. Equity betas are calculated by regressing U.S. dollar firm returns on the Morgan Stanley Capital International (MSCI) World Index over the period 1997-2001. For each firm in each year 1997-2001 we find the market value of equity and book value of debt. We then average these values across the five years for each firm to find firm $i$ 's market value of equity $m v_{i}$ and book value of debt $d_{i}$. We calculate a firm's leverage ratio as $l e v_{i}=\frac{d_{i}}{m v_{i}}$. If some data points are missing, we average across only the years with available data. Complete return and equity, debt and corruption data is available for 3,674 firms from 44 countries. Complete antidirector rights and legal origin data is available for 3,608 firms from 39 countries. Panel B of Table 3 shows that the two corruption measures are highly correlated. Both measures are also highly correlated with per capita GDP.

To test Proposition 6 we examine the relationship between firm betas and our measures of public corruption. A different approach would be to consider surveys of corruption within firms or violations of security market regulations. We are attempting, however, to contrast the effects of corruption (dishonesty) and shareholder rights on firm betas. Tight regulation of firms may discourage realized corruption in the private sector, but we are seeking an empirical measure of the parameter $b$ in the model, which represents managers' predilection to dishonesty, independent of corporate regulations. For this reason, public corruption is a good measure of dishonesty for our purposes since it is likely highly correlated with dishonesty in private firms but government employees are not directly affected by the shareholders' rights regime.

Since we will be making cross-country comparisons, our empirical strategy is essentially to conduct a joint test of the two hypotheses that world capital markets are integrated and that Proposition 6 holds. If world capital markets are indeed integrated, then our model suggests that firms in different countries in the same industry will have asset betas that vary due to differing levels of corruption. Bekaert, Harvey and Lumsdaine (2002) provide evidence on twenty emerging markets that shows that these markets all achieved integration with world capital markets by 
the beginning of our sample period. While their study does not consider several of the countries analyzed here (e.g. China, the Czech Republic, Hungary, Peru, Russia and South Africa), it suggests that the assumption of integrated world markets is not unreasonable. The comprehensive analysis of emerging markets in Harvey (2000) also lends support to the hypothesis of integrated world markets.

Our analysis proceeds in two stages. We first regress monthly U.S. dollar firm returns $r_{i t}$ for each firm $i$ on the MSCI World Index $r_{m t}$ over the five year period January 1997-December 2001 (all firm returns and the MSCI index are calculated with gross dividends reinvested):

$$
r_{i t}=c+\beta r_{m t}+v_{i t},
$$

where $c$ is a constant and $v_{i t}$ is an error term. Equation (6) provides an estimate of firm $i$ 's beta $\hat{\beta}_{i}$ with respect to the world market.

We assign each firm the average corruption rating corr $_{i}$ of its country over the five year period. Each firm is also assigned a $22 x 1$ industry dummy vector $i n d_{i}$. The central regression model is

$$
\hat{\beta}_{i}=a_{1}+a_{2}^{\prime} i n d_{i}+a_{3}\left(l e v_{i}\right)+a_{4}\left(\operatorname{corr}_{i}\right)+u_{i}
$$

where the error term $u_{i}$ is presumed to exhibit potential group-wise clustering at the country level. The premise of this approach is that, aside from the effects of corruption, industry asset betas should be quite similar across different countries. Proposition 6 suggests that corruption can make a firm's asset beta higher. Since we are measuring equity betas, leverage is included as a control. Our two-step approach yields consistent parameter estimates only if the market return is uncorrelated with the error in the beta specification (7), which is not an unreasonable assumption. ${ }^{11}$ The regression results are displayed in Table 4 . The regressions are estimated via ordinary least squares (OLS), with $t$-statistics reported in parentheses using White (1982)-corrected standard errors that account for group-wise clustering at the country level. The first column shows that firms in countries with higher TI scores (i.e. countries with more corruption) have significantly higher betas, controlling for industry. This is the result predicted by Proposition 6. Leverage appears to have little effect on equity betas. Column 2 shows similar results for the GCR corruption measure.

\footnotetext{
${ }^{11}$ An alternative approach is to substitute for $\beta$ in (6) using (7). This allows for a single-step estimation of the coefficient on corruption $a_{4}$. The single-step estimator yields identical coefficient estimates and very similar clustered standard errors.
} 
As displayed in Table 3, there is a strong correlation between corruption and economic development (Mauro, 1995). To dispel the argument that the result linking corruption and higher betas is driven by GDP levels rather than by corruption itself, in the third and fourth columns we include per capita GDP as a control. The corruption coefficients do not change substantially and per capita GDP is insignificant in column 3 and significant in column 4. Despite the high correlation between GDP and corruption, the regressions make clear that corruption increases firm betas.

The magnitudes detailed in Table 4 are substantial. For example, increasing the degree of a country's dishonesty from the level of Canada to that of South Korea would increase the industryadjusted beta of firms by 0.35 (TI estimate from column 1) to 0.42 (GCR estimate from column 2 ). This suggests that countries stricken with corruption exhibit significantly greater sensitivity to world market conditions.

As a robustness check, the two final columns of Table 4 include controls for the origin of the legal system in each country. LLSV (1998) argue that the origin of a country's company law or commercial code can have important effects on finance and may also be related to corruption. The omitted dummy here is English legal origin. The results show that corruption has a large effect on asset betas independent of legal origin.

Our second test evaluates a joint implication of Propositions 3 and 6. Proposition 3 shows that if shareholders retain control, then dishonesty will have no effect on the beta of a firm's assets; the beta will always equal the beta of the firm in the perfect information case. Proposition 6 shows that the firm beta is increasing in the level of dishonesty if the manager has control. It is a prediction of the two propositions taken together, therefore, that firm betas should be more sensitive to corruption when corporate governance is weak and the manager has the power to set the investment level. To test this prediction, we consider the effect of LLSV's (1998) antidirector rights measure.

In the context of our model, we will interpret countries with strong antidirector rights to resemble the legal environment of the information model, in which the shareholders choose the firm's investment policy. When antidirector rights are strong, the board of directors has little choice but to act as the shareholders desire. Countries with weak antidirector rights resemble the control model, in which board-manager collusion is possible and the manager has effective authority.

We regress firm equity betas on leverage, per capita GDP, industry controls and the LLSV measure of antidirector rights. As column 1 of Table 5 shows, increased antidirector rights have 
no effect on firm betas. In the second and third columns of Table 5, we include the corruption measures as controls, and again we find no effect for antidirector rights. The coefficients on the corruption measures are similar to those given in Table 4 . While these results do not show support for the prediction that antidirector rights reduce firm betas in general, it may be that antidirector rights are more important in some countries than in others.

Propositions 3 and 6 together yield a prediction about the effect of the interaction of antidirector rights and dishonesty. When there is little corruption in a country, antidirector rights will have little effect in reducing beta; even in the absence of these rights, the manager will choose the optimal investment policy. When there is substantial dishonesty in a country, however, antidirector rights will be important in reducing overinvestment and hence firm betas.

To test this prediction we include in columns 4 and 5 of Table 5 interactions between antidirector rights and the two corruption measures. The results show that the marginal effect of corruption in increasing beta is highest in countries with few antidirector rights (i.e. the interaction term has a negative coefficient). Dishonesty has the greatest impact when legal institutions do not restrain directors. When antidirector rights are at a level of 4.62 (close to the maximum), corruption has no effect on firm betas. For lower levels of antidirector rights, the effects of dishonesty can be substantial.

This regression also clarifies the antidirector results from the previous two regressions. For a TI (Corruption) level of 3.01 antidirector rights have no effect in reducing firm betas (for reference, France has a TI (Corruption) level of 3.33 and the mean TI (Corruption) is 2.93). For corruption levels around the mean, the marginal effect of antidirector rights is small. Corruption increases firm betas unless antidirector rights are close to the sample maximum, but antidirector rights reduce betas only for fairly high corruption levels.

Increasing corruption has a large impact for even moderate levels of antidirector rights. Switzerland and Turkey both have two rights, and increasing the corruption level from Switzerland's to Turkey's increases the beta by 0.25 . If both countries had three rights, the increase in beta would be 0.16. Both Finland and Brazil have middling rights (three for both). Increasing the level of corruption from that Finland to that of Brazil raises industry-adjusted betas by 0.44 .

The effect of increasing antidirector rights can be considerable when corruption levels are high. For example, Italy has a TI (Corruption) level of 5.11 and Mexico has a TI (Corruption) level of 6.73. Adding one additional right would reduce the predicted beta of Italian firms by 0.098 and 
the beta of Mexican firms by 0.173 . Adding a right in France would reduce the predicted beta by only 0.015 . The predicted effects from the GCR estimates are similar.

Table 6 provides some robustness tests of our main results. The U.S., Japan, and the U.K. are represented strongly in our data set (with 760, 634, and 385 firm observations, respectively). To make clear that these countries are not driving the results, we form a balanced panel limited to the one hundred largest firms in each country, where we rank firms by equity market value. (In 36 of the 44 countries there are fewer than one hundred firms, and all firms from these countries are included.) The results, displayed in the first two columns of the Table, are consistent with the previous evidence.

Morck, Yeung and Yu (2000) find that emerging market stocks exhibit high return synchronicity. They argue that this phenomenon may be explained by greater noise trader activity in developing markets. It might be argued that the corruption-beta link that we document arises from noise trading. For example, the herding into and out of emerging markets as an asset class by international investors might generate the higher betas we find for firms in corruption-prone countries. To test this hypothesis, we restrict the sample to firms from Organisation for Economic Co-operation and Development (OECD) countries. Morck, Yeung and Yu (2000) argue that markets in rich and developed countries are less subject to stock return synchronicity and, possibly, noise trading. There is substantially less variation in corruption measures across the developed OECD countries, so this test of our theory linking corruption to beta is quite stringent. The results, detailed in the third and fourth columns of Table 6, are supportive of our previous findings. The coefficient on corruption is significant at the 10 percent level for TI (Corruption) and at the 1 percent level for GCR (Corruption).

As a final test, we consider the implications of the model for investment. Lemma 4 and Proposition 5 suggest that investment will increase and firm value decrease with corruption. The overinvestment in the model is with respect to the optimal level of investment, which is not observable. Moreover, interpreting the investment level described in our static model in the dynamic context of observed firms is not straightforward. Nevertheless, to supplement the Wurgler (2000) industrylevel results, we gather data from Datastream on firm total asset values. We consider total asset values to be a reasonable proxy for the sum total of firm investments (i.e. total assets is the analogue of investment in our static model). We then divide these asset values by the total value of the firm's equity and debt, and find the median ratio over the five years 1997-2001. Since the model 
does not make predictions about firm scale, we can only test its predictions for the investment(market value) ratio, which is independent of the opportunity level $\delta$. We regress the median (total asset)/(firm value) ratios (for all firms for which data is available) on industry controls and our corruption measures. In the fifth and sixth columns of Table 6 we show that corruption has the predicted positive and significant effect on the ratio of investment (i.e. total assets) to market value. As reported in columns seven and eight of the table, when controlling for GDP per capita the results are weaker and no longer significant for TI (Corruption), though the corruption coefficient remains significant at the 5 percent level in the GCR regression. These results are consistent with those of Claessens, Djankov, Fan and Lang (2002). Given the coarse nature of these tests, we interpret the overall results from these regressions, taken together with Wurgler's findings, to be broadly consistent with the model's predictions.

Our empirical results linking corruption levels to beta are consistent with some previous empirical work. Love (2003) shows that the effective cost of capital is higher in countries with lower levels of financial development. She also finds that corruption raises the cost of capital by tightening financing constraints. In survey results Kaufmann and Wei (1999) show that firms that report paying more bribes also rate their cost of capital as being too high. Lombardo and Pagano (2000) and Hail and Leuz (2003) find that legal institutions affect firms' cost of capital. In a finding that is consistent with our results, Hail and Leuz argue that legal institutions are least important in highly developed countries, which are typically the countries with the lowest corruption levels (in our regressions we distinguish the effects of economic development and corruption).

\section{Conclusion}

We present a model in which shareholders delegate either information or control to managers who may be dishonest. When managers have privileged access to information, they can engage in false reporting to shareholders which diminishes future cash flows by distorting investment. When managers have both information and control, they follow a policy of consistent overinvestment. This further destroys firm value, especially reducing cash flows in the worst states of the world. As a result, the combination of weak corporate governance and managerial dishonesty increases the systematic risk of the firm. In our empirical cross-country analysis we find that corruption (our proxy for dishonesty) substantially increases beta. The effect of corruption on beta is much 
greater in countries in which shareholder rights are weak, which supports our theoretical result that both dishonesty and managerial control are required to generate increased firm betas. While our empirical work is based on international comparisons, our theory suggests that within-country differences may also be important; in the U.S., for example, firms with weaker corporate governance would be predicted to have higher betas and increased costs of capital.

The effects on beta that we document can lead to substantial value destruction and can have important implications for international asset allocation. The real macroeconomic effects may also be significant. In our model, aggregating over firms, countries in which corruption is extensive will have capital stocks that are highly sensitive to world market outcomes. Our empirical results suggest that the additional volatility generated by corruption can be considerable and hence quite costly to risk-averse investors, consumers and employees. Geographically disparate countries with high corruption levels may exhibit more correlated equity performance due to the fact that they have higher betas.

The shareholder-management model we present here may be quite easily applied to other settings, such as the relationship between banks and firms. Our results suggest that when corruption is common, weak enforcement of loan covenants and lenders' rights can lead to investment distortions that are especially costly in the worst states of the world. Consequently, even in economies with relatively small equity markets, one of the costs of tolerating corruption may be particularly severe recessions. 


\section{Appendix}

\subsection{Proof of Lemma 1}

The principal will choose $I_{\emptyset}^{D}(1)$ to maximize his expected profit conditional on the distribution of agents who report $s_{\emptyset}$ when deception is possible. Since the investment granted agents who report their specific types truthfully is increasing in the reported type, it is clear that all types below a given threshold will conceal their signals. We denote this threshold by $q(b)$, and we will show that it exists and has the properties specified in the lemma.

Given $q(b)$, the first order condition for the optimal $I_{\emptyset}^{D}(1)$ is

$$
\frac{E\left[\tilde{r}^{1-\alpha}\right]\left(e \mathrm{E}\left[\tilde{q}^{1-\alpha} \mid \tilde{s}=s_{\emptyset}\right]+(1-b)(1-e) \mathrm{E}\left[\tilde{q}^{1-\alpha} 1_{\{\tilde{q}<q(b)\}}\right]\right)}{e+(1-b)(1-e) \mathrm{E}\left[1_{\{\tilde{q}<q(b)\}}\right]}=I_{\emptyset}^{D}(1)^{1-\alpha} .
$$

Each type below the threshold elects to report $s_{\emptyset}$ and each type above reports $\tilde{s}=q$, so the threshold type must satisfy

$$
q(b)^{1-\alpha} E\left[\tilde{r}^{1-\alpha}\right]=I_{\emptyset}^{D}(1)^{1-\alpha} .
$$

We denote the left hand side of $(8)$ by $G_{1}(q(b))$ and the left hand side of $(9)$ by $G_{2}(q(b))$. The equilibrium condition is that $G_{1}(q(b))=G_{2}(q(b))$. It is clear that $G_{1}\left(q_{\text {min }}\right) \geq G_{2}\left(q_{\text {min }}\right)$ and $G_{1}(\bar{q}) \leq G_{2}(\bar{q})$

The continuity of $G_{1}$ and $G_{2}$ shows that there exists $q(b) \in\left[q_{\min }, \bar{q}\right]$ such that $G_{1}(q(b))=$ $G_{2}(q(b))$. This $q(b)$ is unique. Set $q(b)=\min \left\{q: G_{1}(q)=G_{2}(q)\right\}$. For a contradiction suppose that there exists $\hat{q}>q(b)$ such that $G_{1}(\hat{q})=G_{2}(\hat{q})$. We have

$$
\begin{gathered}
G_{1}(\hat{q})=\frac{E\left[\tilde{r}^{1-\alpha}\right]\left(e \mathrm{E}\left[\tilde{q}^{1-\alpha} \mid \tilde{s}=s_{\emptyset}\right]+(1-b)(1-e)\left(\mathrm{E}\left[\tilde{q}^{1-\alpha} 1_{\{\tilde{q}<q(b)\}}\right]+E\left[\tilde{q}^{1-\alpha} 1_{\{q(b) \leq \tilde{q}<\hat{q}\}}\right]\right)\right)}{e+(1-b)(1-e) \mathrm{E}\left[1_{\{\tilde{q}<\hat{q}\}}\right]} \\
=\frac{E\left[\tilde{r}^{1-\alpha}\right]\left(q(b)^{1-\alpha}\left(e+(1-b)(1-e) \mathrm{E}\left[1_{\{\tilde{q}<q(b)\}}\right]\right)+(1-b)(1-e) E\left[\tilde{q}^{1-\alpha} 1_{\{q(b) \leq \tilde{q}<\hat{q}\}}\right]\right)}{e+(1-b)(1-e) \mathrm{E}\left[1_{\{\tilde{q}<\hat{q}\}}\right]} \\
<\frac{E\left[\tilde{r}^{1-\alpha}\right]\left(\hat{q}^{1-\alpha}\left(e+(1-b)(1-e) \mathrm{E}\left[1_{\{\tilde{q}<q(b)\}}\right]\right)+(1-b)(1-e) \hat{q}^{1-\alpha} E\left[1_{\{q(b) \leq \tilde{q}<\hat{q}\}}\right]\right)}{e+(1-b)(1-e) \mathrm{E}\left[1_{\{\tilde{q}<\hat{q}\}}\right]}
\end{gathered}
$$




$$
=E\left[\tilde{r}^{1-\alpha}\right] \hat{q}^{1-\alpha}=G_{2}(\hat{q}),
$$

which cannot hold.

We may write $G_{1}(q(b), b)$. We have that $\frac{\partial G_{1}}{\partial b}$ has the same sign as

$$
E\left[1_{\{\tilde{q}<q(b)\}}\right] E\left[\tilde{q}^{1-\alpha} \mid \tilde{s}=s_{\emptyset}\right]-E\left[\tilde{q}^{1-\alpha} 1_{\{\tilde{q}<q(b)\}}\right]=E\left[1_{\{\tilde{q}<q(b)\}}\right] \bar{q}^{1-\alpha}-E\left[\tilde{q}^{1-\alpha} 1_{\{\tilde{q}<q(b)\}}\right] \geq 0
$$

We let $b_{2} \geq b_{1}$ be given. The above inequality shows that

$$
G_{1}\left(q\left(b_{1}\right), b_{2}\right) \geq G_{1}\left(q\left(b_{1}\right), b 1\right)=G_{2}\left(q\left(b_{1}\right)\right) .
$$

The work earlier showed that $G_{2}(q)>G_{1}\left(q, b_{2}\right)$ for all $q>q\left(b_{2}\right)$. We conclude that $q\left(b_{1}\right) \leq q\left(b_{2}\right)$.

\subsection{Proof of Lemma 3}

The principal's expected payoff reflects the various cases that may arise. With probability $(1-a)$ deception is not possible, and the profit is therefore identical to that it in the first best, namely $\pi_{h}(r)$. If $m=1$ and deception is possible honest agents who receive a specific signal will report this signal to the principal and the principal's expected payoff will be

$$
\frac{E[\tilde{q}] E\left[\tilde{r}^{1-\alpha}\right]^{\frac{\alpha}{1-\alpha}}}{\alpha}\left[r^{1-\alpha}-\alpha E\left[\tilde{r}^{1-\alpha}\right]\right] .
$$

This case occurs with probability $a b(1-e)$. If $m=1$ and the agent is dishonest, if his signal is specific and $\tilde{q} \geq q(b)$ then the agent prefers to report his signal rather than conceal it. The expected payoff to the principal in this case is

$$
\frac{E\left[\tilde{q} 1_{\{\tilde{q} \geq q(b)\}}\right] E\left[\tilde{r}^{1-\alpha}\right]^{\frac{\alpha}{1-\alpha}}}{E\left[1_{\{\tilde{q} \geq q(b)\}}\right] \alpha}\left[r^{1-\alpha}-\alpha E\left[\tilde{r}^{1-\alpha}\right]\right],
$$

and this case occurs with probability $E\left[1_{\{\tilde{q} \geq q(b)\}}\right] a(1-e)(1-b)$. In the final two cases, $m=1$ and either the agent receives a general signal or the agent is dishonest and receives a specific signal $\tilde{s}=q<q(b)$ and reports $s_{\emptyset}$. This case is analyzed in Lemma 1. The probability weighted profits in this case are given by:

$$
\operatorname{ae}\left(\frac{r^{1-\alpha}}{\alpha} E\left[\tilde{q}^{1-\alpha} \mid \tilde{s}=s_{\emptyset}\right] I_{\emptyset}^{D}(1)^{\alpha}-I_{\emptyset}^{D}(1)\right)
$$




$$
\begin{gathered}
+(1-e)(1-b) E\left[1_{\{\tilde{q} \leq q(b)\}}\right]\left(\frac{r^{1-\alpha}}{\alpha} E\left[\tilde{q}^{1-\alpha} \mid \tilde{q} \leq q(b)\right] I_{\emptyset}^{D}(1)^{\alpha}-I_{\emptyset}^{D}(1)\right) . \\
=a q(b) E\left[\tilde{r}^{1-\alpha}\right]^{\frac{1}{1-\alpha}}\left(\frac{r^{1-\alpha}\left(e E\left[\tilde{q}^{1-\alpha} \mid \tilde{s}=s_{\emptyset}\right]+(1-e)(1-b) E\left[\tilde{q}^{1-\alpha} 1_{\{\tilde{q} \leq q(b)\}}\right]\right)}{\alpha E\left[\tilde{r}^{1-\alpha}\right] q(b)^{1-\alpha}}\right) \\
\left.-a q(b) E\left[\tilde{r}^{1-\alpha}\right]^{\frac{1}{1-\alpha}}\left(e+(1-e)(1-b) E\left[1_{\{\tilde{q} \leq q(b)\}}\right]\right)\right) \\
=a \frac{q(b) E\left[\tilde{r}^{1-\alpha}\right]^{\frac{1}{1-\alpha}}\left(e+(1-e)(1-b) E\left[1_{\{\tilde{q} \leq q(b)\}}\right]\right)}{\alpha E\left[\tilde{r}^{1-\alpha}\right]}\left(r^{1-\alpha}-\alpha E\left[\tilde{r}^{1-\alpha}\right]\right)
\end{gathered}
$$

The first equality follows from Lemma 1 and the second from equations (8) and (9). Combining the cases enumerated above yields the formula for $\pi_{d}(r)$ given in the statement of the lemma.

\subsection{Proof of Proposition 1}

An analysis of the cases detailed in Lemma 2 yields:

$$
\begin{gathered}
E\left[I_{d}(\hat{s}(s, m), m) \mid q\right]=\bar{r} q(1-e)(1-a+a b)+\bar{r} \bar{q}(1-a) e \\
+\bar{r} a(1-b)(1-e) q 1_{\{q \geq q(b)\}}+\bar{r} a q(b)\left(e+(1-e)(1-b) 1_{\{q<q(b)\}}\right) .
\end{gathered}
$$

The result follows from differentiating $E\left[I_{d}(s, m) \mid q\right]$. We note that $E\left[I_{d}(s, m) \mid q\right]$ is not differentiable at $q=q(b)$.

\subsection{Proof of Proposition 2}

We let $b \in[0,1]$ be given.

$$
E\left[\pi_{h}(r)-\pi_{d}(r, b)\right]=\frac{\bar{r}(1-\alpha) a D}{\alpha},
$$

where

$$
D=(1-e)(1-b) E\left[\tilde{q} 1_{\{\tilde{q} \leq q(b)\}}\right]+e \bar{q}-q(b)\left(e+(1-b)(1-e) E\left[1_{\{\tilde{q} \leq q(b)\}}\right]\right) .
$$


We define the event $A$ to be that the signal is specific, the agent is dishonest and $\tilde{q} \leq q(b)$. We define the event $B$ to be that the signal is general. We denote the probability of an event $C$ by $P(C)$. The expression on the right side of (10) may be rewritten as

$$
\begin{gathered}
E[\tilde{q} \mid A] P(A)+E\left[\tilde{q}^{1-\alpha} \mid B\right]^{\frac{1}{1-\alpha}} P(B)-E\left[\tilde{q}^{1-\alpha} \mid A \cup B\right]^{\frac{1}{1-\alpha}} P(A \cup B) \\
\geq E\left[\tilde{q}^{1-\alpha} \mid A\right]^{\frac{1}{1-\alpha}} P(A)+E\left[\tilde{q}^{1-\alpha} \mid B\right]^{\frac{1}{1-\alpha}} P(B)-E\left[\tilde{q}^{1-\alpha} \mid A \cup B\right]^{\frac{1}{1-\alpha}} P(A \cup B) \\
\geq\left[E\left[\tilde{q}^{1-\alpha} \mid A\right] P(A)+E\left[\tilde{q}^{1-\alpha} \mid B\right] P(B)\right]^{\frac{1}{1-\alpha}}-E\left[\tilde{q}^{1-\alpha} \mid A \cup B\right]^{\frac{1}{1-\alpha}} P(A \cup B)=0,
\end{gathered}
$$

where the two inequalities follow from repeated application of Jensen's inequality and the final equality follows from the law of iterated expectations.

\subsection{Proof of Proposition 3}

We let $b_{1}, b_{2} \in[0,1]$ be given. Lemma 3 shows that

$$
\pi_{d}(r, b)=c(b)\left[r^{1-\alpha}-\alpha E\left[\tilde{r}^{1-\alpha}\right]\right]
$$

for a given function $c$ which does not depend on $r$. We thus have that $\frac{p_{d}\left(b_{1}\right)}{p_{d}\left(b_{2}\right)}=\frac{c\left(b_{1}\right)}{c\left(b_{2}\right)}$ and hence $\frac{\pi_{d}\left(r, b_{1}\right)}{p_{d}\left(b_{1}\right)}=\frac{\pi_{d}\left(b_{2}\right)}{p_{d}\left(b_{2}\right)}$. We conclude that

$$
\beta_{d}\left(b_{1}\right)=\frac{\operatorname{cov}\left(\frac{\pi_{d}\left(r, b_{1}\right)}{p_{d}\left(r, b_{1}\right)}, r\right)}{\sigma^{2}}=\frac{\operatorname{cov}\left(\frac{\pi_{d}\left(r, b_{2}\right)}{p_{d}\left(b_{2}\right)}, r\right)}{\sigma^{2}}=\beta_{d}\left(b_{2}\right)
$$

The second statement in the proposition follows from the fact that $\pi_{h}(r)=\pi_{d}(r, 1)$.

\subsection{Proof of Lemma 4}

The strategy of the honest agents is derived in Section 2.1. The investment that maximizes $\pi\left(I, s_{\emptyset}\right)$ is $I=\bar{r} \bar{q}$. If $m=1$ then a dishonest agent has the option to declare $s=s_{\emptyset}$. The agent may thus select $I=\max \left\{\bar{r} \bar{q}, I^{*} q\right\}$. For $q \geq \bar{q}, I^{*} q \geq \bar{q}$ and the agent declares truthfully. If $m=1$ and $q \leq \bar{q}$, the agent declares $s=s_{\emptyset}$. If it is the case that $m=0$, then the agent must declare his quality signal truthfully and choose the investment level as in the honest case. 


\subsection{Proof of Lemma 5}

If the signal is specific and $m=0$ or $m=1$ and the agent is honest then the true quality signal is reported and the investment is $I_{q}^{*}$. These cases occur with probability $(1-e)((1-a)+a b)$. If deception is possible, the agent is dishonest and the signal is specific, for high signals $(\tilde{q} \geq$ $\bar{q})$, the true quality signal is reported and the investment is $I_{q}^{*}$. In all these cases the profit is $\frac{\bar{r}}{\alpha} q\left(r^{1-\alpha}-\alpha E\left[\tilde{r}^{1-\alpha}\right]\right.$ ). If the signal is general (which occurs with probability $e$ ) the investment is $\bar{r} \bar{q}$ and the expected profit (over $q$ outcomes) over these states is $\frac{\bar{r}}{\alpha}\left(r^{1-\alpha}-\alpha E\left[\tilde{r}^{1-\alpha}\right]\right)$. The expression for $K_{1}$ follows from this argument.

If deception is possible, the signal is specific, the agent is dishonest and $\tilde{q} \leq \bar{q}$, the agent will set $I=\bar{r} \bar{q}$. The profit in such a state is

$$
\frac{E\left[\tilde{r}^{1-\alpha}\right]^{\frac{\alpha}{1-\alpha}} \bar{q}}{\alpha}\left(\frac{(r q)^{1-\alpha}}{\bar{q}^{1-\alpha}}-\alpha E\left[\tilde{r}^{1-\alpha}\right]\right) .
$$

The expected profit over all such states is

$$
\begin{gathered}
\frac{E\left[\tilde{r}^{1-\alpha}\right]^{\frac{\alpha}{1-\alpha}} \bar{q}}{\alpha}\left(\frac{r^{1-\alpha} E\left[\tilde{q}^{1-\alpha} 1_{\{\tilde{q} \leq \bar{q}\}}\right]}{\bar{q}^{1-\alpha}}-\alpha E\left[\tilde{r}^{1-\alpha}\right] E\left[1_{\{\tilde{q} \leq \bar{q}\}}\right]\right) \\
=\frac{E\left[\tilde{r}^{1-\alpha}\right]^{\frac{\alpha}{1-\alpha}} \bar{q}^{\alpha} E\left[\tilde{q}^{1-\alpha} 1_{\{\tilde{q} \leq \bar{q}\}}\right]}{\alpha}\left(r^{1-\alpha}-\frac{\alpha E\left[\tilde{r}^{1-\alpha}\right] E\left[1_{\{\tilde{q} \leq \bar{q}\}} \bar{q}^{1-\alpha}\right]}{E\left[\tilde{q}^{1-\alpha} 1_{\{\tilde{q} \leq \bar{q}\}}\right]}\right)
\end{gathered}
$$

The expression for $K_{2}$ is derived from this argument.

\subsection{Proof of Proposition 4}

A straightforward enumeration of the cases detailed in Lemma 4 yields:

$$
E\left[I_{c}(s, m) \mid q\right]=\bar{r}\left(q(1-e)(1-a+a b)+\bar{q} e+a(1-b)(1-e)\left(q 1_{\{q \geq \bar{q}\}}+\bar{q} 1_{\{q<\bar{q}\}}\right)\right) .
$$

The result follows from differentiating $E\left[I_{c}(s, m) \mid q\right]$. We note that $E\left[I_{c}(s, m) \mid q\right]$ is not differentiable at $q=\bar{q}$.

\subsection{Proof of Proposition 5}

We have

$$
\frac{\partial E\left[\pi_{c}(r, b)\right]}{\partial b}=\frac{\bar{r}}{\alpha}\left((1-\alpha) K_{1}^{\prime}(b)+\left(1-\alpha \frac{\bar{q}^{1-\alpha} E\left[1_{\{\tilde{q} \leq \bar{q}\}}\right]}{E\left[\tilde{q}^{1-\alpha} 1_{\{\tilde{q} \leq \bar{q}\}}\right]}\right) K_{2}^{\prime}(b)\right)
$$


We also have

$$
K_{1}^{\prime}(b)=a(1-e)\left(E[\tilde{q}]-E\left[\tilde{q} 1_{\{\tilde{q} \geq \bar{q}\}}\right]\right)>0
$$

and

$$
K_{2}^{\prime}(b)=-a(1-e) \bar{q}^{\alpha} E\left[\tilde{q}^{1-\alpha} 1_{\{\tilde{q} \leq \bar{q}\}}\right]<0 .
$$

This implies that

$$
\frac{\partial E\left[\pi_{c}(r, b)\right]}{\partial b}=\frac{\bar{r} a(1-e)}{\alpha}\left((1-\alpha) E\left[\tilde{q} 1_{\{\tilde{q} \leq \bar{q}\}}\right]-\bar{q}^{\alpha} E\left[\tilde{q}^{1-\alpha} 1_{\{\tilde{q} \leq \bar{q}\}}\right]+\alpha \bar{q} E\left[1_{\{\tilde{q} \leq \bar{q}\}}\right]\right) \geq 0,
$$

where the inequality follows from

$$
g(q)=(1-\alpha) q+\alpha \bar{q}-\bar{q}^{\alpha} q^{1-\alpha} \geq 0
$$

for $q \leq \bar{q}$. (We have $g(\bar{q})=0$ and $g^{\prime}(q)=(1-\alpha)-(1-\alpha)\left(\frac{\bar{q}}{q}\right)^{\alpha} \leq 0$ for all $q \leq \bar{q}$.)

To show that the principal's profit is higher when the agent does not have control, we first examine the equilibrium investments described in Lemmas 2 and 4 . These lemmas show that $I_{d}$ differs from $I_{c}$ only in the two following cases:

1. If $m=1$ and $s=q \in(q(b), \bar{q}), I_{d}(\hat{s}(s, m), m)=I_{q}^{*}$ and $I_{c}(s, m)=\bar{r} \bar{q}$.

2. If $m=1$ and $s=s_{\emptyset}$ or if $m=1$ and $s=q \leq q(b), I_{d}(\hat{s}(s, m), m)=\bar{r} q(b)$ and $I_{c}(s, m)=\bar{r} \bar{q}$.

Since $I_{q}^{*}$ is always the optimal investment it is clear that the principal does better when he has control if the event described in case 1 occurs.

For case 2 , we let $b \in[0,1]$ be given and we set $A=(m=1) \cup\left(\left(s=s_{\emptyset}\right) \cap(s=q \leq q(b))\right)$. Equations (8) and (9) show that for all $(s, m) \in A$

$$
I_{d}(\hat{s}(s, m), m)=\bar{r} q(b)=\operatorname{argmax}_{I} E[\pi(I, s) \mid A] .
$$

We conclude that the principal's expected profit is always higher when he has control:

$$
E\left[\pi_{c}(r, b)\right]=E\left[\pi\left(I_{c}, s\right)\right] \leq E\left[\pi\left(I_{d}, s\right)\right]=E\left[\pi_{d}(r, b)\right] .
$$




\subsection{Proof of Proposition 6}

We may write

$$
\pi_{c}(r, b)=c_{2}(b)\left(r^{1-\alpha}-\alpha E\left[\tilde{r}^{1-\alpha}\right] \gamma(b)\right)
$$

where $c_{2}(b)$ does not depend on $r$ and

$$
\gamma(b)=\frac{K_{1}(b)+K_{2}(b) \frac{\bar{q}^{1-\alpha} E\left[1_{\{\tilde{q} \leq \bar{q}\}}\right]}{E\left[\tilde{q}^{1-\alpha} 1_{\{\tilde{q} \leq \bar{q}\}}\right]}}{K_{1}(b)+K_{2}(b)} \geq 1 .
$$

A straightforward calculation shows that $\gamma^{\prime}(b)$ has the same sign as

$$
\left(\frac{\bar{q}^{1-\alpha} E\left[1_{\{\tilde{q} \leq \bar{q}\}}\right]}{E\left[\tilde{q}^{1-\alpha} 1_{\{\tilde{q} \leq \bar{q}\}}\right]}-1\right)\left(K_{1}(b) K_{2}^{\prime}(b)-K_{1}^{\prime}(b) K_{2}(b)\right)<0 .
$$

We showed in the proof of Proposition 3 that the beta of $\pi_{d}$ is equal to the beta of $\left(r^{1-\alpha}-\alpha E\left[\tilde{r}^{1-\alpha}\right]\right)$ and by analogous argument the beta of $\pi_{c}$ is equal to the beta of $\left(r^{1-\alpha}-\alpha E\left[\tilde{r}^{1-\alpha}\right] \gamma(b)\right)$. We define $\hat{p}_{c}(b)$ to be the price of $\left(r^{1-\alpha}-\alpha E\left[\tilde{r}^{1-\alpha}\right] \gamma(b)\right)$. We have

$$
\beta_{c}(b)=\frac{\operatorname{cov}\left(\frac{r^{1-\alpha}-\alpha E\left[\tilde{r}^{1-\alpha}\right] \gamma(b)}{\hat{p}_{c}(b)}, r\right)}{\sigma^{2}}=\frac{\operatorname{cov}\left(r^{1-\alpha}, r\right)}{\hat{p}_{c}(b) \sigma^{2}}
$$

and, hence,

$$
\frac{\partial \beta_{c}(b)}{\partial b}=\frac{-\operatorname{cov}\left(r^{1-\alpha}, r\right)}{\hat{p}_{c}^{2}(b) \sigma^{2}} \hat{p}_{c}^{\prime}(b)<0,
$$

where the inequality follows from the definition of $\hat{p}_{c}(b)$ and the fact that $\gamma^{\prime}(b)<0$. 


\section{References}

Ades, Alberto, and Rafael Di Tella, "Rents, Competition and Corruption," American Economic Review, 89 (1999), 982-993.

Aghion, Philippe, and Jean Tirole, "Formal and Real Authority in Organizations," The Journal of Political Economy, 105 (1997), 1-29.

Almeida, Heitor, and Daniel Wolfenzon, "The Effect of External Finance on the Equilibrium Allocation of Capital," working paper (2003).

Beck, Thorsten, Asli Demirguc-Kunt, and Ross Levine, "Law, endowments, and finance," Journal of Financial Economics, 70 (2003), 137-181.

Bekaert, Geert, Campbell R. Harvey, and Robin L. Lumsdaine, "Dating the integration of world equity markets," Journal of Financial Economics, 65 (2002), 203-247.

Bhattacharya, Upal, Hazem Daouk, and Michael Welker, "The World Price of Earnings Opacity," working paper (2002).

Botosan, Christine, "Disclosure Level and the Cost of Equity Capital", The Accounting Review, 72 (1997), 323-349.

Claessens, S., S. Djankov, J. Fan and L. Lang, "Disentangling the Incentive and Entrenchment Effects of Large Shareholdings", Journal of Finance, 57 (2002), 2741-71.

Clarke, George R.G., and Lixin Colin Xu, "Ownership, Competition, and Corruption: Bribe Takers versus Bribe Payers," working paper, World Bank (2002).

Core, John E., Robert W. Holthausen, and David F. Larcker, "Corporate governance, chief executive officer compensation, and firm performance," Journal of Financial Economics, 51 (1999), 371-406.

Easley, David, Soeren Hvidkjaer, and Maureen O'Hara, "Is Information Risk a Determinant of Asset Returns?", Journal of Finance, 57 (2002), 2185-2221.

Easley, David, and Maureen O'Hara, "Information and the Cost of Capital", forthcoming, Journal of Finance, (2004).

Erard, Brian, and Jonathan Feinstein, "Honesty and Evasion in the Tax Compliance Game," Rand Journal of Economics, 25 (1994), 1-19.

Gompers, Paul, Ishii, Joy, and Andrew Metrick, "Corporate Governance and Equity Prices," Quarterly Journal of Economics, 118 (2003), 107-155.

Grossman, Sanford, and Oliver Hart, "The Costs and Benefits of Ownership: A Theory of Vertical and Lateral Integration," Journal of Political Economy, 94 (1986), 691-719.

Guiso, Luigi, Paola Sapienza, and Luigi Zingales, "The Role of Social Capital in Financial Development," working paper, University of Chicago (2003).

Hail, Luzi, and Christian Leuz, "International Differences in Cost of Capital: Do Legal Institutions and Securities Regulations Matter?", working paper (2003).

Harvey, Campbell R., "Drivers of Expected Returns in International Markets," Emerging Markets Quarterly, 4 (2000), 32-48. 
Himmelberg, Charles P., R. Glenn Hubbard and Inessa Love, "Investor Protection, Ownership, and the Cost of Capital," working paper (2002).

Kaufmann, Daniel, and Shang-Jin Wei, "Does 'Grease Money' Speed Up the Wheels of Commerce," NBER working paper (1999).

La Porta, Rafael, Florencio Lopez-de-Silanes, Andrei Shleifer, and Robert Vishny, "Legal Determinants of External Finance," Journal of Finance, 52 (1997), 1131-1150.

La Porta, Rafael, Florencio Lopez-de-Silanes, Andrei Shleifer, and Robert Vishny, "Law and Finance," Journal of Political Economy, 106 (1998), 1113-1155.

La Porta, Rafael, Florencio Lopez-de-Silanes, Andrei Shleifer, and Robert Vishny, "Corporate Ownership around the World," Journal of Finance, 54 (1999), 471-517.

La Porta, Rafael, Florencio Lopez-de-Silanes, Andrei Shleifer, and Robert Vishny, "Investor Protection and Corporate Governance," Journal of Financial Economics, 58 (2000), 3-27.

Lombardo, Davide, and Marco Pagano, "Legal determinants of the return on equity", working paper (2000).

Love, Inessa, "Financial Development and Financing Constraints: International Evidence from the Structural Investment Model," Review of Financial Studies, 16 (2003), 765-791.

Mauro, Paolo, "Corruption and Growth," Quarterly Journal of Economics, 110 (1995), 681-712.

Morck, Randall, Bernard Yeung, and Wayne Yu, "The information content of stock markets: why do emerging markets have synchronous stock price movements?", Journal of Financial Economics, 58 (2000), 215-260.

Myers, Stewart C., and Nicholas S. Majluf, "Corporate Financing and Investment Decisions When Firms Have Information that Investors Do Not Have," Journal of Financial Economics, 13 (1984), 187-221.

Shleifer, Andrei, and Robert Vishny, "Corruption," Quarterly Journal of Economics, 108 (1993), 599-617.

Shleifer, Andrei, and Robert Vishny, "Politicians and Firms," Quarterly Journal of Economics , 109 (1994), 995-1025.

Shleifer, Andrei, and Robert Vishny, "A Survey of Corporate Governance," Journal of Finance , 52 (1997), 737-783.

Shleifer, Andrei, and Daniel Wolfenzon, "Investor protection and equity markets," Journal of Financial Economics, 66 (2002), 3-27.

Treisman, Daniel, "The causes of corruption: a cross-national study," Journal of Public Economics, 76 (2000), 399-457.

Wei, Shang-Jin, "How Taxing is Corruption on International Investors?", NBER working paper (1997).

Wei, Shang-Jin, "Natural Openness and Good Government," NBER working paper (2000).

Wurgler, Jeffrey, "Financial markets and the allocation of capital," Journal of Financial Economics, 58 (2000), 187-214. 
Table 2: List of Countries

\begin{tabular}{llll}
\hline \hline 1. Argentina & 2. Australia & 3. Austria & 4. Belgium \\
5. Brazil & 6. Canada & 7. Chile & 8. China \\
9. Colombia & 10. Czech Republic & 11. Denmark & 12. Finland \\
13. France & 14. Germany & 15. Greece & 16. Hong Kong \\
17. Hungary & 18. India & 19. Indonesia & 20. Ireland \\
21. Israel & 22. Italy & 23. Japan & 24. Malaysia \\
25. Mexico & 26. Netherlands. & 27. New Zealand & 28. Norway \\
29. Peru & 30. Philippines & 31. Poland & 32. Portugal \\
33. Russian Federation & 34. Singapore & 35. South Africa & 36. South Korea \\
37. Spain & 38. Sweden & 39. Switzerland & 40. Taiwan \\
41. Thailand & 42. Turkey & 43. United Kingdom & 44. United States \\
\hline \hline
\end{tabular}


Table 3: Summary Statistics

\begin{tabular}{lrrrr}
\hline \hline Panel A: Variable Distribution Characteristics \\
& & & & Std \\
& Number & Mean & Median & Dev \\
\cline { 2 - 5 } Equity Beta & 3,674 & 0.81 & 0.70 & 0.62 \\
Leverage & 3,674 & 0.29 & 0.24 & 0.23 \\
GDP & 44 & 24.14 & 24.80 & 8.48 \\
TI (Corr) & 44 & 2.93 & 2.40 & 1.67 \\
GCR (Corr) & 44 & 1.21 & 0.87 & 0.85 \\
AD Rts & 39 & 3.89 & 4 & 1.27 \\
Common Law & 39 & 0.515 & 1 & 0.50
\end{tabular}

Panel B: Correlation Table

\begin{tabular}{|c|c|c|c|c|c|c|c|}
\hline & $\begin{array}{r}\text { Equity } \\
\text { Beta }\end{array}$ & Leverage & GDP & $\begin{array}{r}\mathrm{TI} \\
\text { (Corr) }\end{array}$ & $\begin{array}{r}\text { GCR } \\
\text { (Corr) }\end{array}$ & AD Rts & $\begin{array}{c}\text { Common } \\
\text { Law }\end{array}$ \\
\hline Equity Beta & 1.00 & -0.05 & -0.12 & 0.17 & 0.23 & -0.04 & 0.08 \\
\hline Leverage & & 1.00 & -0.04 & 0.06 & 0.08 & -0.17 & -0.14 \\
\hline GDP & & & 1.00 & -0.60 & -0.70 & 0.32 & 0.27 \\
\hline TI (Corr) & & & & 1.00 & 0.92 & -0.24 & -0.30 \\
\hline GCR (Corr) & & & & & 1.00 & -0.31 & -0.18 \\
\hline AD Rts & & & & & & 1.00 & 0.70 \\
\hline Common Law & & & & & & & 1.00 \\
\hline
\end{tabular}

Panel A reports the number of distinct observations, mean, median, and standard deviation for each variable. Firm equity betas are estimated by regressing total U.S. dollar returns on the MSCI World Index over the period January 1997 to December 2001. Leverage is the ratio of book value of debt to (book value of debt+market value of equity). All other variables are measured at the country level and attributed to firms. Means, medians and standard deviations are calculated for country variables at the firm level. GDP is the per capita GDP in 2001 in thousands of U.S. dollars. TI(Corr) is the average Transparency International Corruption Perception Index for annual reports over 1997-2001. GCR(Corr) is the average Global Competitiveness Report irregular payments score over the annual reports 1997-2000 and the combined report of 2001-2002. AD Rts is an aggregate of shareholder antidirector rights for controlling boards of directors, drawn from LLSV (1998). Common Law is a dummy variables equal to one if a country's company law or commercial code is designed according to common law principles,drawn from LLSV (1998). Panel B presents the correlations between variables, treating each firm as an observation. The correlations are given for the sample of firms with all data items available. 
Table 4: Corruption and Beta

\begin{tabular}{|c|c|c|c|c|c|c|}
\hline & \multicolumn{6}{|c|}{ Dependent Variable = Firm Equity Beta } \\
\hline TI (Corr) & $\begin{array}{c}0.070^{* *} \\
(2.32)\end{array}$ & & $\begin{array}{c}0.064^{* *} \\
(2.03)\end{array}$ & & $\begin{array}{c}0.084^{* *} \\
(2.12)\end{array}$ & \\
\hline GCR (Corr) & & $\begin{array}{c}0.175^{* *} \\
(2.64)\end{array}$ & & $\begin{array}{c}0.217^{* *} \\
(3.27)\end{array}$ & & $\begin{array}{c}0.233^{* *} \\
(2.58)\end{array}$ \\
\hline Leverage & $\begin{array}{l}-0.011 \\
(-0.09)\end{array}$ & $\begin{array}{l}-0.026 \\
(-0.22)\end{array}$ & $\begin{array}{l}-0.011 \\
(-0.09)\end{array}$ & $\begin{array}{l}-0.030 \\
(-0.26)\end{array}$ & $\begin{array}{l}0.020 \\
(0.16)\end{array}$ & $\begin{array}{l}-0.004 \\
(-0.04)\end{array}$ \\
\hline GDP & & & $\begin{array}{c}-0.0020 \\
(-0.38)\end{array}$ & $\begin{array}{c}0.0058^{*} \\
(1.86)\end{array}$ & $\begin{array}{c}-0.0018 \\
(-0.34)\end{array}$ & $\begin{array}{c}0.0044 \\
(0.90)\end{array}$ \\
\hline French Origin & & & & & $\begin{array}{l}-0.150 \\
(-1.10)\end{array}$ & $\begin{array}{l}-0.141 \\
(-1.06)\end{array}$ \\
\hline German Origin & & & & & $\begin{array}{c}-0.218^{* *} \\
(-2.23)\end{array}$ & $\begin{array}{c}-0.142^{*} \\
(-1.79)\end{array}$ \\
\hline Scandinavian Origin & & & & & $\begin{array}{l}0.008 \\
(0.07)\end{array}$ & $\begin{array}{l}-0.001 \\
(-0.01)\end{array}$ \\
\hline
\end{tabular}

Results from the regression of estimated firm betas (over the period January 1997 to December 2001) with respect to the MSCI World Index on measures of corruption. TI (Corr) is the average Transparency International Corruption Perception Index for annual reports over 1997-2001. Leverage is the ratio of book value of debt to (book value of debt+market value of equity). GCR (Corr) is the average Global Competitiveness Report irregular payments score over the annual reports 1997-2000 and the combined report of 2001-2002. GDP is the per capita GDP in 2001 in thousands of U.S. dollars. French, German and Scandinavian Origin are dummy variables for the legal origin of a country's company law or commercial code, drawn from LLSV (1998). Controls include a constant and 22 industry dummies drawn from the Global Industry Classification System. The regressions are estimated via ordinary least squares (OLS), with $t$-statistics reported in parentheses using White (1982)-corrected standard errors that account for group-wise clustering at the country level. The coefficients on the constant and industry dummy terms are not reported for brevity.

*,** Indicates significance at the $10 \%$ and $5 \%$ levels, respectively. 
Table 5: Shareholder Rights, Corruption and Beta

\begin{tabular}{lccccc}
\hline \hline & \multicolumn{6}{c}{ Dependent Variable $=$ Firm Equity Beta } \\
\hline & -0.003 & 0.000 & 0.009 & $0.140^{* *}$ & $0.142^{* *}$ \\
AD Rts & $(-0.08)$ & $(0.00)$ & $(0.29)$ & $(2.07)$ & $(2.54)$ \\
TI (Corruption) & & $0.063^{*}$ & & $0.215^{* *}$ & \\
& & $(1.96)$ & & $(3.41)$ & \\
GCR (Corruption) & & & $0.225^{* *}$ & & $0.538^{* *}$ \\
& & & $(3.08)$ & & $(4.14)$ \\
AD Rts * TI (Corruption) & & & & $-0.047^{* *}$ & \\
& & & & $(-2.43)$ & \\
AD Rts * GCR (Corruption) & & & & & $-0.100^{* *}$ \\
& & & & & $(-2.49)$ \\
Leverage & -0.012 & -0.022 & -0.029 & -0.058 & -0.068 \\
GDP & $(-0.10)$ & $(-0.18)$ & & $(-0.52)$ & $(-0.64)$ \\
& -0.0092 & -0.0021 & 0.0056 & -0.0039 & 0.0015 \\
& $(-1.35)$ & $(-0.35)$ & $(1.48)$ & $(-0.61)$ & $(0.26)$ \\
\hline \hline
\end{tabular}

Results from the regression of estimated firm betas (over the period January 1997 to December 2001) with respect to the MSCI World Index on measures of corruption. AD Rts is an aggregate of shareholder antidirector rights for controlling boards of directors, drawn from LLSV (1998). TI (Corr) is the average Transparency International Corruption Perception Index for annual reports over 1997-2001. GCR (Corr) is the average Global Competitiveness Report irregular payments score over the annual reports 1997-2000 and the combined report of 2001-2002. Leverage is the ratio of book value of debt to (book value of debt+market value of equity). GDP is the per capita GDP in 2001 in thousands of U.S. dollars. Controls include a constant and 22 industry dummies drawn from the Global Industry Classification System. The regressions are estimated via ordinary least squares (OLS), with $t$-statistics reported in parentheses using White (1982)-corrected standard errors that account for group-wise clustering at the country level. The coefficients on the constant and industry dummy terms are not reported for brevity.

*,** Indicates significance at the $10 \%$ and $5 \%$ levels, respectively. 
Table 6: Robustness Tests

\begin{tabular}{|c|c|c|c|c|c|c|c|c|}
\hline $\begin{array}{r}\text { Dep Var } \\
\# O b s .\end{array}$ & $\begin{array}{c}\text { Beta } \\
\text { Balanced } \\
2064 \\
\end{array}$ & $\begin{array}{c}\text { Beta } \\
\text { Balanced } \\
2064 \\
\end{array}$ & $\begin{array}{c}\text { Beta } \\
\text { OECD } \\
3079 \\
\end{array}$ & $\begin{array}{r}\text { Beta } \\
\text { OECD } \\
3079 \\
\end{array}$ & $\begin{array}{c}\mathrm{TA} / \mathrm{MV} \\
2441 \\
\end{array}$ & $\begin{array}{c}\mathrm{TA} / \mathrm{MV} \\
2441 \\
\end{array}$ & $\begin{array}{c}\mathrm{TA} / \mathrm{MV} \\
2441 \\
\end{array}$ & $\begin{array}{c}\text { TA/MV } \\
2441 \\
\end{array}$ \\
\hline TI (Corr) & $\begin{array}{c}0.067^{* *} \\
(2.43)\end{array}$ & & $\begin{array}{c}0.058^{*} \\
(1.80)\end{array}$ & & $\begin{array}{c}0.234^{* *} \\
(2.79)\end{array}$ & & $\begin{array}{l}0.106 \\
(1.48)\end{array}$ & \\
\hline GCR (Corr) & & $\begin{array}{c}0.196^{* *} \\
(2.91)\end{array}$ & & $\begin{array}{c}0.223^{* *} \\
(2.82)\end{array}$ & & $\begin{array}{c}0.602^{* *} \\
(2.92)\end{array}$ & & $\begin{array}{c}0.447^{* *} \\
(2.10)\end{array}$ \\
\hline Leverage & $\begin{array}{l}0.069 \\
(0.46)\end{array}$ & $\begin{array}{l}0.039 \\
(0.28)\end{array}$ & $\begin{array}{l}-0.097 \\
(-1.01)\end{array}$ & $\begin{array}{l}-0.120 \\
(-1.34)\end{array}$ & & & & \\
\hline GDP & $\begin{array}{c}0.0002 \\
(0.03)\end{array}$ & $\begin{array}{c}0.0076 \\
(1.09)\end{array}$ & $\begin{array}{l}0.0022 \\
(0.45)\end{array}$ & $\begin{array}{c}0.0073^{* *} \\
(2.30)\end{array}$ & & & $\begin{array}{c}-0.046^{* *} \\
(-3.16)\end{array}$ & $\begin{array}{c}-0.024^{*} \\
(-1.76)\end{array}$ \\
\hline
\end{tabular}

Results from the regressions of firm betas and (total asset/market value) ratios on measures of corruption. Beta is the estimated firm beta (over the period January 1997 to December 2001) with respect to the MSCI World Index. TA/MV is the median ratio of firm total assets to market value of equity and debt over the years 1997-2001. The Balanced columns include a maximum of 100 firms per country. The OECD columns include only firms from Organisation for Economic Co-operation and Development countries. TI (Corr) is the average Transparency International Corruption Perception Index for annual reports over 1997-2001. GCR (Corr) is the average Global Competitiveness Report irregular payments score over the annual reports 1997-2000 and the combined report of 2001-2002. Leverage is the ratio of book value of debt to (book value of debt+market value of equity). GDP is the per capita GDP in 2001 in thousands of U.S. dollars. Controls include a constant and 22 industry dummies drawn from the Global Industry Classification System. The regressions are estimated via ordinary least squares (OLS), with $t$-statistics reported in parentheses using White (1982)-corrected standard errors that account for group-wise clustering at the country level. The coefficients on the constant and industry dummy terms are not reported for brevity.

*** Indicates significance at the $10 \%$ and $5 \%$ levels, respectively. 